\title{
Atividades de Trigonometria para o Ensino Fundamental com o uso do software GeoGebra
}

\author{
Trigonometry activities in Elementary Education with GeoGebra software
}

\author{
Ezequiel Bobsin Strasburg ${ }^{1}$, Fabíola Aiub Sperotto ${ }^{2}$, \\ e Cinthya Maria Schneider Meneghetti ${ }^{3}$ \\ ${ }^{1}$ Mestrado em andamento em PROFMAT - Mestrado Profissional em Matemática. \\ Universidade Federal do Rio Grande, FURG, Brasil. \\ ezequielstrasburg@yahoo.com.br \\ ${ }^{2,3}$ Universidade Federal do Rio Grande, RS, Brasil \\ fabiolasperotto@furg.br; cinthyaschneider@furg.br
}

\begin{abstract}
Resumo
Este trabalho tem como objetivo apresentar novas atividades para o ensino de trigonometria no Ensino Fundamental. A ideia é mostrar como ensinar as principais relações trigonométricas através de exercícios que levam os alunos, de forma gradual, à obtenção dessas relações. As atividades sugeridas fazem uso do software GeoGebra, um recurso que possibilita a construção de círculos trigonométricos que facilitam o entendimento por parte dos alunos. Este trabalho apresenta ainda, não somente as relações seno, cosseno e tangente para ângulos agudos, como normalmente é proposto por livros didáticos do $9^{\circ}$ ano do Ensino Fundamental, mas também relações como secante, cossecante e cotangente. Além disso, não se limita à ângulos agudos e ao estudo de triângulos retângulos, deixando, assim, o aluno mais preparado para os desafios do Ensino Médio e da vida profissional.
\end{abstract} Palavras-chave: Trigonometria, relações trigonométricas, círculo trigonométrico.

\begin{abstract}
This work aims to present new activities for teaching trigonometry in Elementary Education. The idea is to show how to teach the main trigonometric relations through exercises that guide students, gradually, to conclusions of these trigonometry relations. The suggested activities make use of "GeoGebra "software, a feature that enables the construction of trigonometric circles that facilitate the understanding by students. This paper presents not only the sine relations, cosine and tangent for acute angles, as it is usually proposed by textbooks $9^{\text {th }}$ year of elementary school, but also relationships with secant, cosecant and cotangent, and it is not limited to acute angles and the study of right triangles, this leaving, the student more prepared for the challenges of high school and to their professional life.
\end{abstract}

Keywords: Trigonometry, trigonometric relationships, trigonometric circle. 


\section{Introdução}

Com o avanço da tecnologia e o surgimento de novas ferramentas computacionais, a informática está cada vez mais presente no cotidiano das escolas. Desta forma, cabe ao professor buscar novas metodologias e práticas pedagógicas visando um ensino mais atrativo, multidisciplinar, que desperte o interesse do educando e facilite o processo pedagógico.

Segundo Dante (1999),

\begin{abstract}
O mundo está em constantes mudanças, dado o grande e o rápido desenvolvimento da tecnologia - Máquinas de calcular, computadores, internet, etc, são assuntos do dia-a-dia e todos eles têm ligações estreitas com a Matemática. Nas últimas décadas, muitos pesquisadores da psicologia cognitiva se dedicaram a estudar e pesquisar como os alunos aprendem, como aplicam o que aprendem para resolver situações problemas, como constroem conceitos, qual é a maturidade cognitiva necessária para se apropriar com significado, determinado conceito, como a interação com o meio social desenvolve a aprendizagem.
\end{abstract}

O professor diante deste fato deve estar sempre buscando uma atualização profissional, pois a formação do professor é fundamental para acompanhar a demanda de uma sociedade em transformação.

A incessante busca por uma nova estratégia de ensino da Matemática, visando sanar algumas dificuldades e despertando o interesse do educando é uma tarefa que nem sempre é fácil de realizar. Com o uso das Tecnologias da Informação e Comunicação (TIC's), os professores tem disponíveis diversos recursos como os softwares livres, que não necessitam de pagamento de licenças. Um destes softwares é o GeoGebra. O software GeoGebra (aglutinação das palavras Geometria e Álgebra) é um aplicativo de matemática dinâmica que combina conceitos de geometria e álgebra. Sua distribuição é livre, nos termos da GNU General Public License, e é escrito em linguagem Java, o que lhe permite estar disponível em várias plataformas. Este software possui ferramentas que podem ser usadas tanto no Ensino Fundamental como nos Ensinos Médio e Superior.

O estudo da trigonometria é parte importante do desenvolvimento da Matemática. Os primeiros estudos surgiram na Grécia há mais de 2 mil anos devido aos problemas gerados em navegação, agrimensura e astronomia. As dúvidas em astronomia levaram os gregos à grandes conclusões na época como: o diâmetro da Terra, a distância da Lua e a distância do Sol. Atualmente, a trigonometria tem aplicações em vários ramos do conhecimento: na Matemática, Física, Medicina ou em qualquer fenômeno cíclico que pode ser descrito por uma função trigonométrica.

Muitos educandos do $9^{\circ}$ ano do Ensino Fundamental encontram dificuldades de aprendizagem no estudo da Matemática, em especial quando se trata de trigonometria. O estudo da trigonometria é guiado através de livros didáticos e explicações de professores, que muitas vezes se limitam apenas nas aplicações de fórmulas de razões trigonométricas, as quais costumam ser decoradas sem entendimento mais expressivo e vazio de significado. Também é comum que os alunos tenham acesso à tabela trigonométrica com valores de seno, cosseno e tangente de cada ângulo onde, na grande maioria das vezes, não sabem de onde surgiram. Muitos livros sequer fazem menção à existência do círculo trigonométrico e se limitam à explicações de seno, cosseno e tangente de um ângulo $\alpha$ para $0^{\circ}<\alpha<90^{\circ}$.

Sendo assim, este trabalho traz uma proposta de uso de novos recursos tecnológicos, mais especificamente o uso do software GeoGebra no ensino da trigonometria. Além disso, sugere-se trabalhar não apenas seno, cosseno e tangente, mas também a secante, cossecante e cotangente de um ângulo, e apresentar ângulos quaisquer, não apenas variando entre $0^{\circ}$ e $90^{\circ}$. Também não nos restringiremos ao estudo do triângulo retângulo.

Este trabalho tem o propósito de mostrar aos alunos a importância do estudo da trigonometria e apresentar noções bem fundamentadas, entender significado das fórmulas e dos valores da tabela trigonométrica e capacitá-los para utilizar os conhecimentos trigonométricos no dia-a-dia.

Com intuito de servir como facilitador para os professores, este trabalho também apresenta a construção no software GeoGebra do círculo trigonométrico e o círculo trigonométrico de Hiparco.

Na sequência, o trabalho traz uma proposta de atividades para o ensino de trigonometria no $9^{\circ}$ ano do Ensino Fundamental, com o uso das construções feitas no software GeoGebra. Esta proposta tem a intenção de auxiliar os alunos a aprenderem de forma gradual, sem a necessidade de decorar fórmulas, desenvolvendo neles a capacidade de aplicar os conhecimentos trigonométricos construídos.

\section{Estudo da Trigonometria}

Segundo Libâneo (2001) "A escola com que sonhamos é aquela que assegura a todos a formação cultural e científica para a vida pessoal, profissional e cidadã,..."

Ainda sobre essas falas e reflexões o mesmo autor relata:

A escola tem concorrentes poderosos, inclusive que pretendem substituir suas funções, como as 
mídias, os computadores e até propostas que querem fazer dela meramente um lugar de convivência social. Acho vital compreender que efetivamente estamos de frente a novos desafios. Em face desse contexto, a escola precisa manter aquelas funções nucleares de que falei, mas, simultaneamente, precisa rever processos, os métodos, as formas de educar, ensinar e aprender. Para que isso aconteça, é preciso que os professores compreendam que a escola não é mais a única agência de transmissão do saber. Na verdade, ela nunca deteve sozinha nesse papel, mas hoje é fundamental que os educadores percebam que a educação ocorre em muitos lugares... (LIBÂNEO, em entrevista a Costa (2007))

Neste contexto, é importante que os educadores tenham compreensão de que é necessária a adaptação da escola às mudanças da sociedade, inclusive na forma de se construir conhecimento. Fica evidente que uma das formas de se adaptar, é usar novas agências de transmissão do saber não como concorrentes, mas em prol de uma educação de qualidade.

Quanto à trigonometria, o professor pode fazer uso de recursos tecnológicos que facilitarão a aprendizagem dessa importante área do conhecimento que já contribuiu muito com o desenvolvimento científico.

Algumas noções sobre trigonometria são estudadas no $9^{\circ}$ ano do Ensino Fundamental, com aplicações de razões trigonométricas no triângulo retângulo e no Ensino Médio os estudos se intensificam com funções trigonométricas normalmente no $1^{\mathrm{O}}$ ano, e prosseguem em alguns cursos de Ensino Superior pela utilidade que têm em vários ramos do conhecimento. É comum os vestibulares e o ENEM (Exame Nacional do Ensino Médio) apresentarem questões referentes à este conteúdo.

\section{Abordagem dada ao estudo de tri- gonometria em livros didáticos}

Esta seção apresenta uma análise da abordagem da trigonometria em 5, dos 10 livros didáticos do $9^{\circ}$ ano do Ensino Fundamental, colocados a disposição dos professores da rede pública de ensino pelo MEC (Ministério da Educação e Cultura) através do PNLD 2014 (Programa Nacional do Livro Didático). Os livros analisados são: Matemática - Bianchini Bianchini (2012), Matemática - ideias e desafios Onaga e Mori (2012), Matemática: teoria e contexto Centurión e Jakubovic (2012), Projeto Araribá Matemática de Leonardo (2013) e Vontade de saber Matemática Souza e Pataro (2012).

Nestes livros, o conteúdo de trigonometria é apresentado, em geral, com algum resumo da história, exemplos de aplicação, bem como as definições de seno, cosseno e tangente para ângulos agudos no triângulo retângulo e o estudo das razões trigonométricas com ângulos notáveis.

Os diferenciais de Bianchini (2012) são: mostrar ao leitor como usar a calculadora científica para encontrar os valores de seno, cosseno e tangente; explicar o que é teodolito (aparelho usado para medir ângulos) e como construir um teodolito com transferidor, que pode ser interessante para ser trabalhado em sala de aula.

Os diferenciais de Onaga e Mori (2012) são: uma linguagem acessível ao leitor e a construção de um instrumento para determinar os valores de seno e cosseno para ângulos maiores que $0^{\circ}$ e menores que $90^{\circ}$ que reproduz o primeiro quadrante do círculo trigonométrico.

O livro de Centurión e Jakubovic (2012): estimula a aplicação dos conhecimentos na prática; apresenta o conteúdo de forma bem ilustrada e apresenta a curiosidade de como calcular o raio da Terra.

O autor de Leonardo (2013): apresenta relações entre seno, cosseno e tangente e mostra ao leitor como usar a calculadora científica para encontrar os valores de seno, cosseno e tangente.

Os diferenciais de Souza e Pataro (2012) são: expor o conteúdo de forma bem ilustrada e com muitos detalhes; conter um número expressivo de exercícios e explicar ao leitor como usar um software, que oferece a possibilidade de encontrar medidas de ângulos e lados de triângulos, chamado Microsoft Mathematics.

Nenhum dos atuais livros analisados menciona a existência do círculo trigonométrico, embora o livro Onaga e Mori (2012) apresente um instrumento para encontrar os valores de seno e cosseno de um ângulo agudo, que é uma reprodução do primeiro quadrante do círculo. Os livros analisados definem seno como a razão entre a medida do cateto oposto e a medida da hipotenusa em um triângulo retângulo; o cosseno como a razão entre a medida do cateto adjacente e a medida da hipotenusa e a tangente como a razão entre a medida do cateto oposto e a medida do cateto adjacente em um triângulo retângulo, ou seja, definem seno, cosseno e tangente apenas para ângulos agudos. Nenhum desses livros faz referência à secante, cossecante, e cotangente, e quase nada se fala a respeito de outras relações trigonométricas. Esses livros se limitam ao estudo da trigonometria em triângulos retângulos, não fazendo referência à trigonometria em um triângulo qualquer. Consequentemente, não fazem referência a lei dos senos e a lei dos cossenos. Embora o livro Vontade de saber Matemática (de Souza e Pataro (2012)) apresente como usar o programa Microsoft Mathematics, livros que usam recursos tecnológicos são exceções.

É importante que os alunos do $9^{\circ}$ ano do Ensino Fundamental estudem secante, cossecante e cotangente, assim como trigonometria em um triângulo qualquer. Além disso, saibam o significado das palavras seno, cosseno, tangente, secante, cossecante e cotangente e 
conheçam o círculo trigonométrico pois através dele é possível chegar às razões e relações trigonométricas sem a necessidade de decorar. Além disso, sejam estimulados a usar softwares de maneira correta, pois dessa forma chegam ao Ensino Médio mais preparados para aprender as funções trigonométricas.

\section{Justificativa e objetivos}

Segundo os Parâmetros Curriculares Nacionais MEC (1998) do terceiro e quarto ciclos do Ensino Fundamental, no que se refere à importância dos recursos tecnológicos na educação:

\begin{abstract}
O mundo vive um acelerado desenvolvimento, em que a tecnologia está presente direta ou indiretamente em atividades bastante comuns. A escola faz parte do mundo e para cumprir sua função de contribuir para a formação de indivíduos que possam exercer plenamente sua cidadania, participando dos processos de transformação e construção da realidade, deve estar aberta e incorporar novos hábitos, comportamentos, percepções e demandas.
\end{abstract}

A principal motivação para a elaboração deste trabalho deve-se à inquietação diante das experiências negativas acumuladas com aulas de trigonometria através de métodos tradicionais. Além disso, existem: a inconformidade com a dificuldade dos alunos em entender um conteúdo tão rico e útil; o fato da grande maioria dos livros didáticos não apresentarem uma forma de levar os alunos a concluírem as relações trigonométricas e a vontade de buscar melhores resultados fazendo algo diferenciado daquilo que é apresentado nos livros didáticos atuais.

Nossa intenção é estimular o uso de recursos tecnológicos em sala de aula, oferecer aos professores uma forma alternativa de ensino da trigonometria e servir como facilitador para esses professores. Além disso, eliminar, ou pelo menos reduzir, as experiências frustrantes dos professores no ensino deste conteúdo, dar aos alunos os conhecimentos em trigonometria necessários para que tenham condições entender a importância desse tema, aplicar esse conhecimento na prática e no Ensino Médio. Este trabalho quer servir como complemento aos livros didáticos.

\section{Construção do círculo de Hiparco}

Nesta seção apresenta-se uma forma de construção para o círculo de Hiparco que pode ser feita em duas versões que se diferem na forma como se modifica o ângulo.
1. Verificar se os eixos $x$ e $y$ estão expostos na janela de visualização, reposicionar a figura para o lugar desejado e ajustar seu tamanho;

2. Criar um valor positivo na janela de álgebra, que será a medida do raio, na barra de entrada, digitar um valor positivo qualquer (preferencialmente menor ou igual a 3 , usando ponto para separar a parte inteira da parte decimal caso preferir um número decimal), e pressionar a tecla enter, criando o valor $a$;

\section{Observação:}

(a) É possível criar qualquer valor positivo para $a$, porém, dependendo do valor escolhido será difícil a visualização, ou será necessário repetir o item 1. Portanto não use valores elevados.

\section{Renomear o valor $a$ para $r$;}

4. Criar o círculo de raio $r$, na barra de recursos, escolher opção círculo dados centro e raio. $\mathrm{Na}$ janela de visualização, clicar na origem do plano cartesiano $(0,0)$ e abrirá nova janela, em seguida, digitar $r$, e clicar no botão OK, criando assim os pontos $A$ e o círculo $c$ de raio $r$;

5. Criar o ponto de interseção entre o círculo $c$ e o eixo $x$ positivo $(r, 0)$, criando o ponto $B$;

6. Criar um ponto qualquer sobre o círculo $c$, diferente de $B$ (preferencialmente do arco do primeiro quadrante), criando o ponto $C$;

7. Criar o ponto de reflexão de $C$ em relação ao eixo $x$, em: barra de recursos, escolher a opção reflexão em relação a uma reta. Na janela de visualização, clicar no ponto $C$, depois clicar em um ponto do eixo $x$, com exceções dos pontos $A$ e $B$, criando o ponto $C^{\prime}$;

8. Traçar os segmentos de reta $\overline{A B}, \overline{A C}, \overline{A C^{\prime}}$ e $\overline{C C^{\prime}}$;

9. Criar os ângulos $B \widehat{A} C$ e $C^{\prime} \widehat{A} B$, em: barra de recursos, clicar no botão 8 , depois clicar na opção ângulo, conforme a Figura 11. Na janela de visualização, clicar no ponto $B$, depois clicar no ponto $A$, e por fim, clicar no ponto $C$, criando o ângulo $\alpha=B \widehat{A} C$, em seguida, clicar no ponto $C^{\prime}$, depois clicar no ponto $A$, e por fim, clicar no ponto $B$, criando o ângulo $\beta=C^{\prime} \widehat{A} B=\alpha$;

10. Criar o ponto de interseção entre os segmentos $\overline{A B}$ e $\overline{C C^{\prime}}$, criando o ponto $D$;

11. Traçar os segmentos de reta $\overline{C D}$ e $\overline{A D}$;

12. Renomear aos valores $e, f$, e $g$ respectivamente como $\overline{C C^{\prime}}, \overline{C D}$ e $\overline{A D}$; 
13. Ocultar rótulos, esconder eixos $x$ e $y$, mudar rótulo de posição.

A Figura 1 mostra o Círculo trigonométrico de Hiparco.

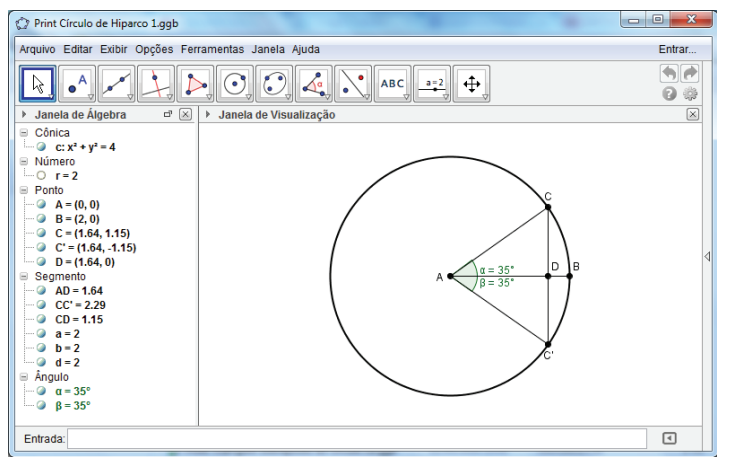

Figura 1: Círculo trigonométrico de Hiparco

Para alterar a medida do raio do círculo de Hiparco, digitar a medida do raio (por exemplo: $r=1.5$ ), e pressionar a tecla enter. Também pode-se alterar o raio do círculo de Hiparco com a opção 1 da barra de recursos, depois clicar na opção mover. Na janela de visualização, clicar no ponto $B$ e arrastar horizontalmente.

É possível alterar a medida do ângulo em: barra de recursos, clicar no botão 1, depois clicar na opção mover. Na janela de visualização clicar no ponto $C$ e arrastar sobre o círculo $c$. O professor também pode criar uma versão 2 do círculo de Hiparco digitando o ângulo na barra de entrada.

Com o Círculo de Hiparco o professor tem uma interessante ferramenta para uso em sala de aula, podendo ser utilizado para comparar um triângulo qualquer a um triângulo semelhante deste círculo.

Atividade 5.1 (Estudando o círculo trigonométrico de Hiparco). Esta atividade tem o propósito de mostrar aos alunos como se iniciou o estudo da trigonometria e como surgiu o círculo trigonométrico. Nesta atividade usaremos a construção feita na seção 5 .

$\mathrm{O}$ uso do círculo trigonométrico de Hiparco feito no software GeoGebra, se torna interessante pelo dinamismo. O professor pode, inclusive, realizar a construção do círculo de Hiparco com régua e compasso, mas a vantagem da construção no software GeoGebra é a precisão e também tornar possível o uso de medidas dos lados dos triângulos que são expostas na janela de álgebra.

Objetivos: Estimular os alunos ao uso de recursos tecnológicos na aprendizagem; mostrar aos alunos como surgiu o primeiro círculo trigonométrico usando as mesmas ideias de Hiparco e explicar o surgimento da palavra seno.

Pré-requisitos: Semelhança e congruência de triângulos; Teorema de Pitágoras; Propriedades da proporção e conhecimentos mínimos sobre utilização do software GeoGebra.
Material necessário: Equipamento que tenha instalado o software GeoGebra, além do material escolar usual.

Tempo necessário: 2 horas/aula.

Exercício 1. Leitura: Há aproximadamente 500 a.C. os gregos, especialmente Pitágoras de Samos (569 a 475 a.C., aproximadamente), já tinham conhecimento da relação entre os catetos e a hipotenusa de um triângulo retângulo, inclusive com demonstração, conhecida como Teorema de Pitágoras, em que era possível calcular a medida de um dos lados de um triângulo retângulo conhecidas as medidas dos outros dois lados. No entanto, nos estudos de astronomia do grego Hiparco de Nicéia (190 a 125 a.C.), considerado o "Pai da trigonometria ", surgiu a necessidade de saber como calcular um dos lados do triângulo retângulo sabendo-se apenas a medida de um dos catetos e um dos ângulos agudos. Hiparco, fazendo uso dos conhecimentos em semelhança de triângulos propostos por Tales de Mileto (624 a 548 a.C.), criou o que podemos chamar de "primeiro círculo trigonométrico", com a finalidade de encontrar triângulos semelhantes e compará-los.

Sabendo-se dessa importância, faça as atividades a seguir:

a) No círculo de Hiparco, construído no software GeoGebra, escolha um valor qualquer para a medida do raio, e um valor qualquer para a medida do ângulo $\alpha$ (Escolha entre o círculos de Hiparco 1 e 2);

b) No círculo criado no item (a), justifique que os triângulos $A C D$ e $A C^{\prime} D$ são congruentes, e consequentemente, são triângulos retângulos:

c) Encontre um triângulo, no círculo de Hiparco do software GeoGebra, que seja semelhante ao triângulo $E F G$, da Figura 2, e calcule o valor de $x$ por semelhança de triângulos, usando o valor da medida do segmento $\overline{C D}$ (correspondente à meia corda $\overline{C C^{\prime}}$ ) exposto na janela de álgebra.

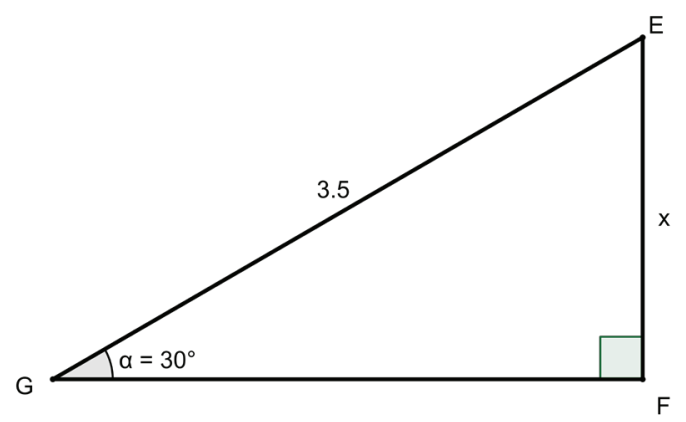

Figura 2: Atividade 5.1, exercício 1, item (c) - Triângulo EFG

d) Repita o que foi feito no item (c), porém utilizando raio unitário no círculo de Hiparco. 


\section{Solução da Atividade 5.1: Exercício 1}

a) Uma possível solução: para mudar a medida do raio deve-se digitar na barra de entrada um valor para o raio, por exemplo $r=1.5$, e pressionar a tecla enter. Também é possível alterar a medida do raio em: barra de recursos, clicar no botão 1, depois clicar na opção mover e na janela de visualização, arrastar o ponto $B$ horizontalmente. Para mudar a medida do ângulo deve-se, na barra de recursos, clicar no botão 1 , depois clicar na opção mover e na janela de visualização arrastar o ponto $C$ sobre o círculo. Veja a Figura 3.

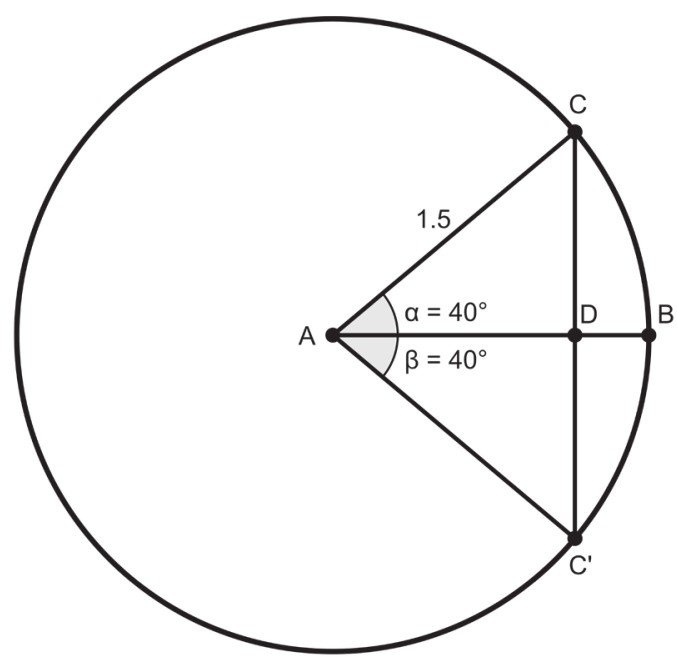

Figura 3: Atividade 5.1, exercício 1, item (a) - Solução

b) Analisando a figura construída no item (a), podese perceber que a medida do lado $\overline{A C}$ é igual à medida do lado $\overline{A C^{\prime}}$, a medida do ângulo $\alpha$ é igual à medida do ângulo $\beta$, e o lado $\overline{A D}$ é comum ao triângulo $A C D$ e $A C^{\prime} D$, portanto $\triangle A C D$ e $\triangle A C^{\prime} D$ são congruentes por LAL (possuem dois lados correspondentes congruentes e os ângulos compreendidos entre esses lados congruentes). Como esses triângulos são congruentes, tem-se que os ângu$\operatorname{los} C \widehat{D} A$ e $A \widehat{D} C^{\prime}$ são congruentes. Como $C \widehat{D} A$ e $A \widehat{D} C^{\prime}$ são suplementares, a soma de suas medidas é igual a $180^{\circ}$, portanto os ângulos $C \widehat{D} A$ e $A \widehat{D} C^{\prime}$ são retos e, consequentemente $\triangle A C D$ e $\triangle A C^{\prime} D$ são triângulos retângulos.

c) Uma possível solução: primeiramente vamos encontrar no círculo de Hiparco, um triângulo semelhante ao triângulo retângulo $E F G$ e, para isso, podemos utilizar a construção feita no item (a), com raio medindo 1,5, em seguida alterar o ângulo $\alpha$ para $30^{\circ}$. Para isso deve-se, na barra de recursos, clicar no botão 1, depois clicar na opção mover e na janela de visualização arrastar o ponto $C$ sobre o círculo até encontrar $\alpha=30^{\circ}$. Veja a Figura 4 .

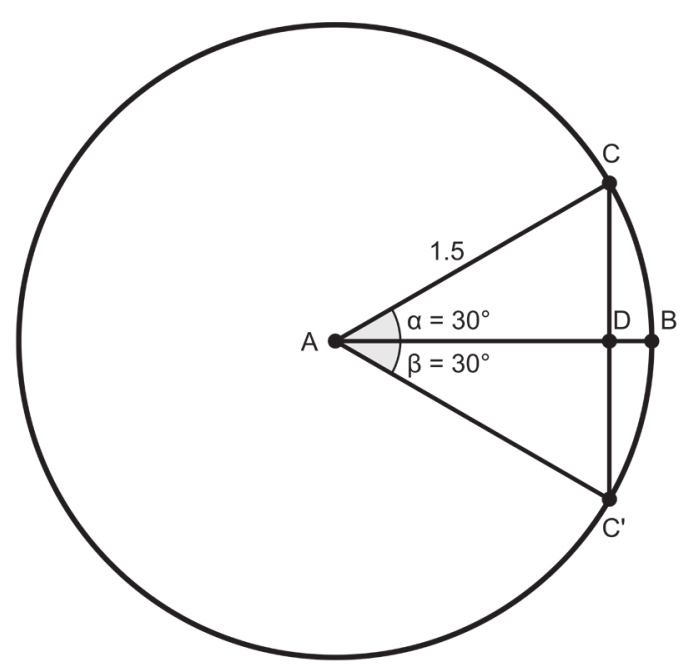

Figura 4: Atividade 5.1, exercício 1, item (c) - Solução

Conforme vimos no item (b), o triângulo $A C D$ é retângulo. Portanto, o triângulo $A C D$ é semelhante ao triângulo $E F G$ por AA (possuem dois ângulos correspondentes congruentes, e consequentemente o terceiro ângulo congruente). Como os triângulos $E F G$ e $A C D$ são semelhantes possuem os lados correspondentes proporcionais, então é possível encontrar o valor de $x$ comparando esses dois triângulos, usando as medidas de $\overline{A C}=1,5 \mathrm{e}$ $\overline{C D}=0,75$, na janela de álgebra:

$$
\begin{gathered}
\frac{\overline{C D}}{\overline{E F}}=\frac{\overline{A C}}{\overline{F G}} \Leftrightarrow \frac{\overline{C D}}{\overline{A C}}=\frac{\overline{E F}}{\overline{F G}} \Leftrightarrow \frac{0,75}{1,5}=\frac{x}{3,5} \Leftrightarrow \\
1,5 x=2,625 \Leftrightarrow x=1,75 .
\end{gathered}
$$

Portanto, o triângulo EFG tem a medida $x=\overline{E F}=$ 1,75 .

d) O círculo construído no item (c) já apresenta o triângulo $A C D$ semelhante ao triângulo $E F G$, porém o raio não é unitário. Para deixar o raio igual a 1 , basta digitar $r=1$ na barra de entrada e pressionar a tecla enter. Dessa maneira, $\overline{A C}=1$ e $\overline{C D}=0,5$. Portanto:

$\frac{\overline{C D}}{\overline{E F}}=\frac{\overline{A C}}{\overline{F G}} \Leftrightarrow \frac{\overline{C D}}{\overline{A C}}=\frac{\overline{E F}}{\overline{F G}} \Leftrightarrow \frac{0,5}{1}=\frac{x}{3,5} \Leftrightarrow x=1,75$.

Portanto, o triângulo $E F G$ tem a medida $x=\overline{E F}=$ 1,75 . 


\section{Dicas ao professor:}

1. Mostre aos alunos que o círculo de Hiparco no software GeoGebra, possibilita encontrar todas as possibilidades de triângulos retângulos;

2. Diga aos alunos que um triângulo qualquer pode ser comparado a um triângulo semelhante no círculo de Hiparco com raio qualquer, porém é mais fácil comparar esse triângulo a um triângulo que tenha um dos lados unitário. Esse é o motivo pelo qual o círculo trigonométrico atual, que será mostrado aos alunos na sequência, tem raio unitário;

3. Para calcular o valor de $x$ foi preciso utilizar a medida de $\overline{D C}$, que corresponde à metade da corda $\overline{C C^{\prime}}$. Então peça para os alunos que observem que quando se altera o ângulo $\alpha$, se altera também a medida da meia corda $\overline{C D}$;

4. Comente com os alunos que será estudado, posteriormente, uma fórmula que relaciona a medida do ângulo $\alpha$ à medida da meia corda $\overline{C D}$. Esta fórmula generaliza o que foi feito nesta atividade e é chamada de relação seno.

Importante: a relação entre o ângulo $\alpha$ e a meia corda $\overline{C D}$, era chamada de função meia corda. A palavra em sânscrito para "meia corda"era jya-ardha, que era abreviada por jiva. Em árabe isso se tornou jiba, que se abrevia por $j b$. Tradutores latinos tornaram erroneamente $j b$ pela palavra árabe jaib, que singnifica seio, portanto passaram a usar a palavra latina sinus, e em português sinus tornou-se seno.

\section{Círculo trigonométrico 1: seno, cos- seno e tangente}

O círculo trigonométrico 1 apresentará os valores de seno, cosseno e tangente de um ângulo $\alpha$ e esta seção apresenta duas construções para o círculo trigonométrico 1, que diferem na forma como se altera o ângulo. Estas construções serão chamadas de círculo trigonométrico 1a e círculo trigonométrico 1b. Os detalhes da construção dos círculos trigonométricos estão no trabalho de conclusão de mestrado Strasburg (2014) que está disponível em www.profmat.furg.br. Na próxima subseção descreveremos os passos principais das construções.

\subsection{Construção do círculo trigonométrico 1a}

1. Exibir os eixos $x$ e $y$ na janela de visualização, conforme a Figura 5;

2. Na janela de visualização, arrastar a figura para centralizar os eixos, conforme a Figura 6;

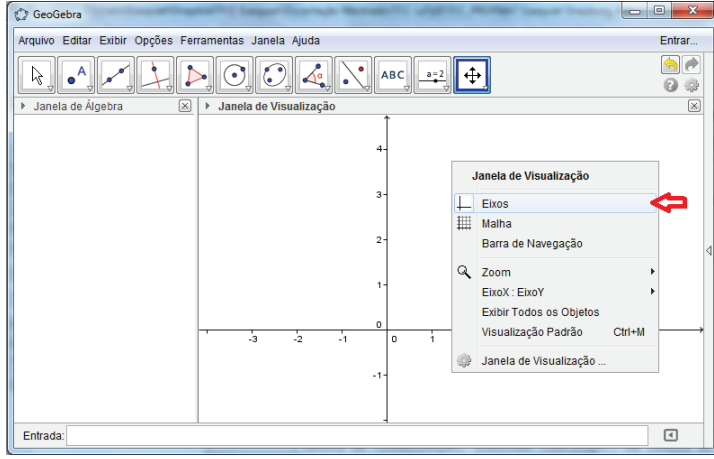

Figura 5: Ativar, ou desativar, eixos $x$ e $y$

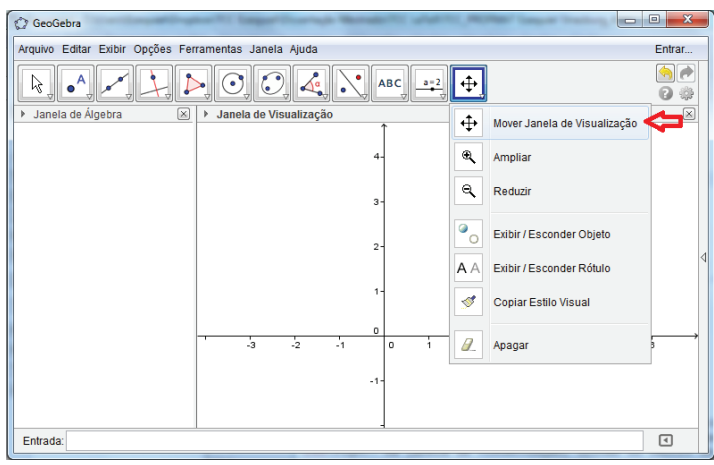

Figura 6: Mover janela de visualização

3. Ajustar o tamanho da figura de acordo com que se deseja. Veja a Figura 7;

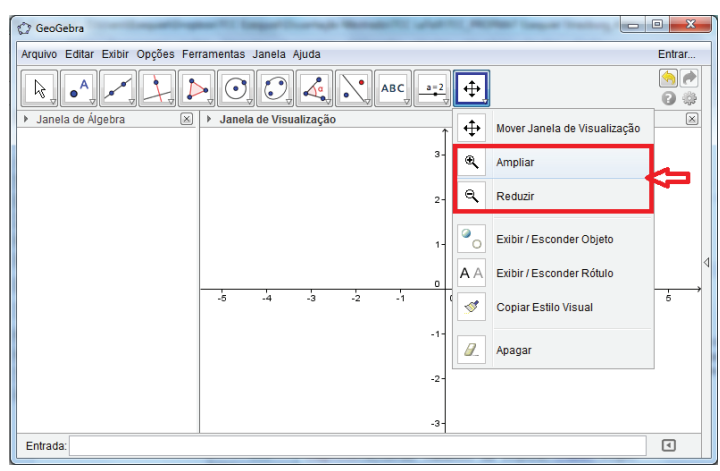

Figura 7: Ajustar tamanho da figura

4. Criar o círculo de raio unitário: escolher a opção círculo dados centro e um de seus pontos, conforme a Figura 8. Na janela de visualização, clicar na origem do plano cartesiano $(0,0)$ e em seguida clicar no ponto $(1,0)$, criando assim os pontos $A$ e $B$ e o círculo $c$ de raio unitário e centrado na origem;

5. Criar um ponto $C$ qualquer sobre o círculo $c$ em: 


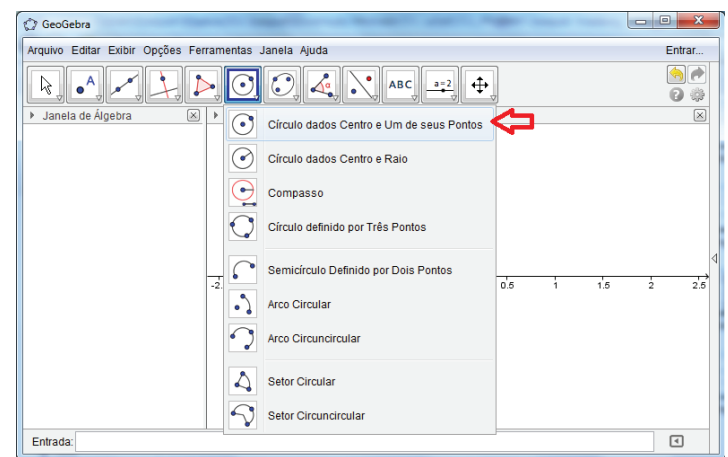

Figura 8: Criar círculo

barra de recursos, clicar no botão 2, depois clicar na opção ponto, conforme a Figura 9. Na janela de visualização, clicar em um ponto qualquer do círculo $c$;

\section{Observações:}

(a) $\mathrm{O}$ ponto $C$ não deve ser um dos pontos de interseção entre o eixo y e o círculo $c$ pelo fato da tangente de um ângulo não estar definida para os ângulos de $90^{\circ}$ e $270^{\circ}$;

(b) Evite escolher um ponto próximo a um dos pontos de interseção entre o eixo $y$ e o círculo $c$, pois isso pode dificultar a construção da figura.

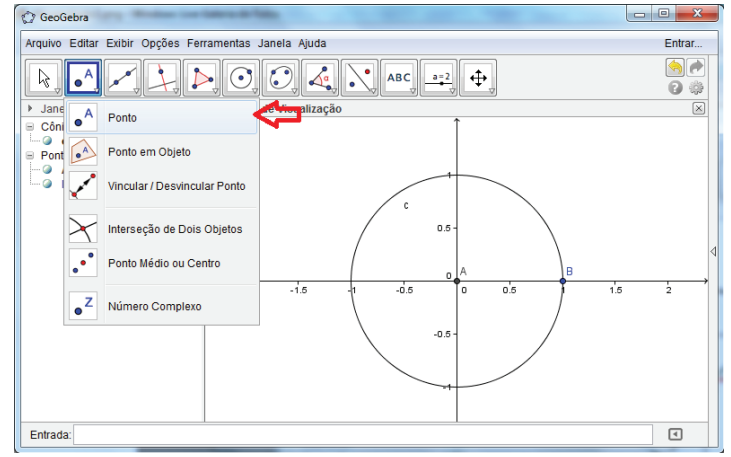

Figura 9: Criar ponto

6. Traçar o segmento de reta $\overline{A C}$. Na janela de visualização, clicar no ponto $A(0,0)$ e depois clicar no ponto $C$, criando o segmento de reta $a=\overline{A C}$. Veja Figura 10;

7. Criar o ângulo $B \widehat{A} C$ (veja Figura 11). Na janela de visualização, clicar no ponto $B$, depois clicar no ponto $A$, e por fim, clicar no ponto $C$, criando o ângulo $\alpha=B \widehat{A} C$;

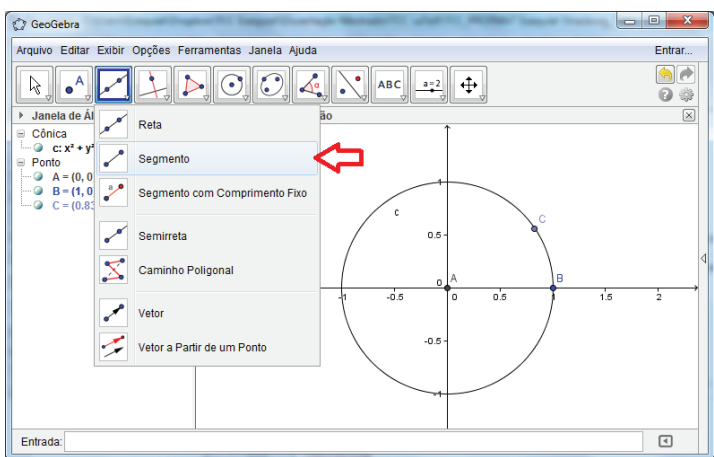

Figura 10: Traçar segmento de reta

(a) Vale ressaltar que a ordem dos pontos em que clicamos altera a figura do ângulo.

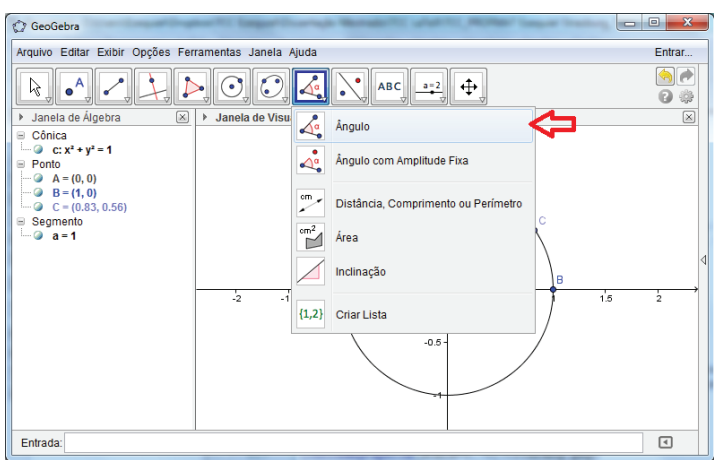

Figura 11: Criar ângulo

8. Traçar a reta tangente ao círculo $c$ (Figura 12), pelo ponto $(1,0)$;

\section{Observação:}

(a) O software GeoGebra não criará a reta tangente ao clicar nos pontos $B$ e $C$, por esse motivo o ponto $C$ não pode ser escolhido para essa construção.

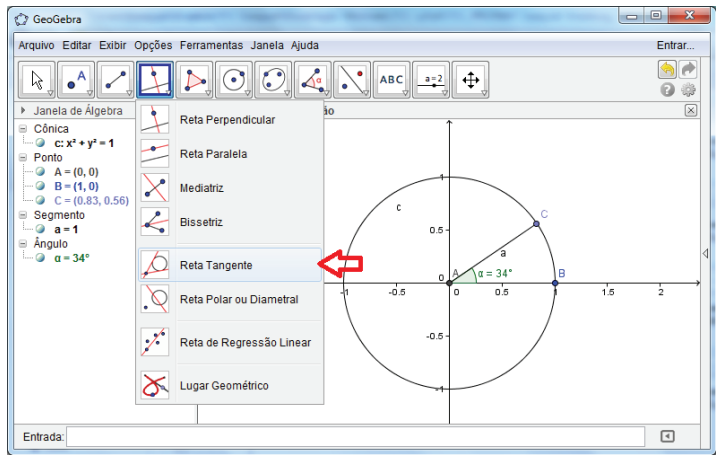

Figura 12: Traçar reta tangente ao círculo 
9. Criar o ponto $D$ que contém a tangente de $\alpha$ na coordenada $y$, sobre a reta $b$, em: barra de entrada, digitar o ponto $(1, \operatorname{tg}(\alpha))$, conforme a Figura 13;

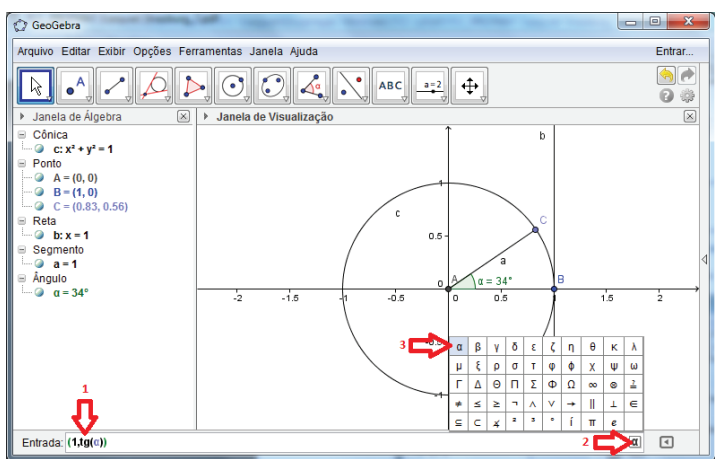

Figura 13: Ponto com tangente do ângulo na coordenada $y$, na reta $b$

10. Criar o ponto $E$ que contém o cosseno de $\alpha$ na coordenada $x$, sobre o eixo $x$, em: barra de entrada, digitar o ponto $(\cos (\alpha), 0)$, conforme a Figura 14;

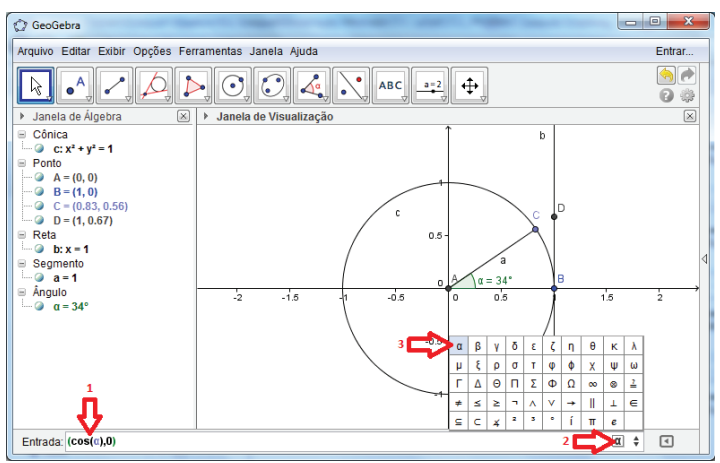

Figura 14: Ponto com cosseno do ângulo na coordenada $x$, no eixo $x$

11. Criar o ponto $F$ que contém o seno de $\alpha$ na coordenada $y$, sobre o eixo $y$, em: barra de entrada, digitar o ponto $(0, \operatorname{sen}(\alpha))$, conforme a Figura 15;

12. Traçar os segmentos de reta $\overline{A D}, \overline{C E}, \overline{C F}, \overline{A F}, \overline{A E}$ e $\overline{B D}$;

13. Escrever os valores de seno, cosseno e tangente na janela de álgebra, da seguinte forma: digitar na barra de entrada $\operatorname{sen}(\alpha)$ e pressionar a tecla enter criando o valor $j$. Depois repetir o processo digitando $\cos (\alpha)$ e pressionando a tecla enter para criar o valor $k$, e por fim, digitando $\tan (\alpha)$ e pressionando a tecla enter para criar o valor $l$ (conforme Figura 16);

14. Renomear os valores $j, k$ e $l$, na janela de álgebra, clicar com botão direito do mouse em j, e abrirá

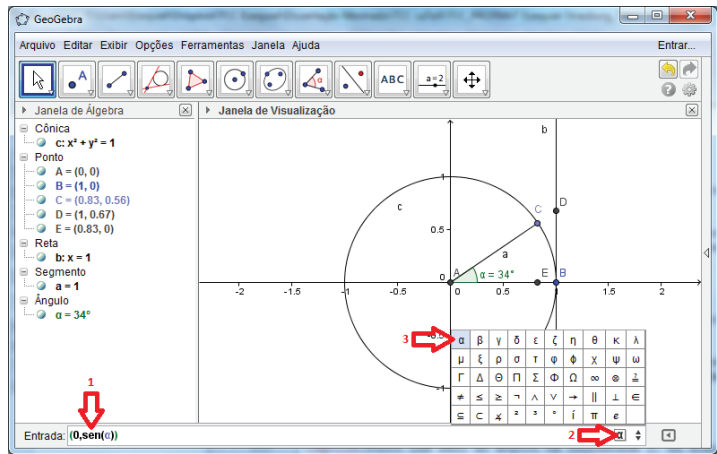

Figura 15: Ponto com seno do ângulo na coordenada $y$, no eixo $y$

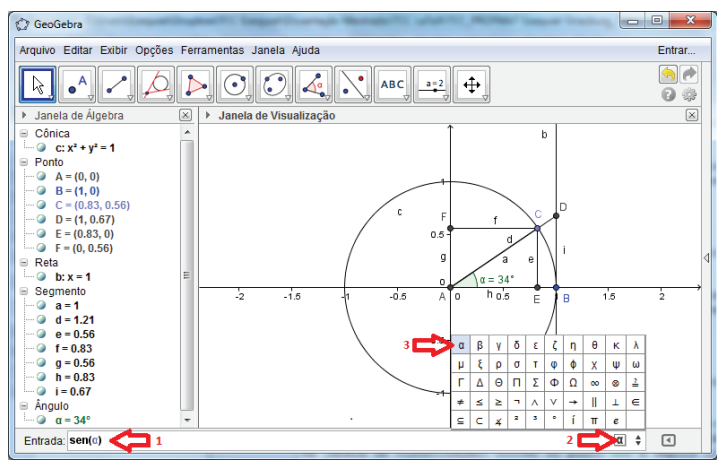

Figura 16: Criar o valor de seno na janela de álgebra

uma nova janela. Deve-se clicar no botão renomear. Será aberta outra janela, em seguida, digitar seno e clicar no botão OK, conforme as Figuras 17 e 18. Repetir o processo com o valor $k$ dando o nome de cosseno, e com o valor $l$ dando o nome de tangente;

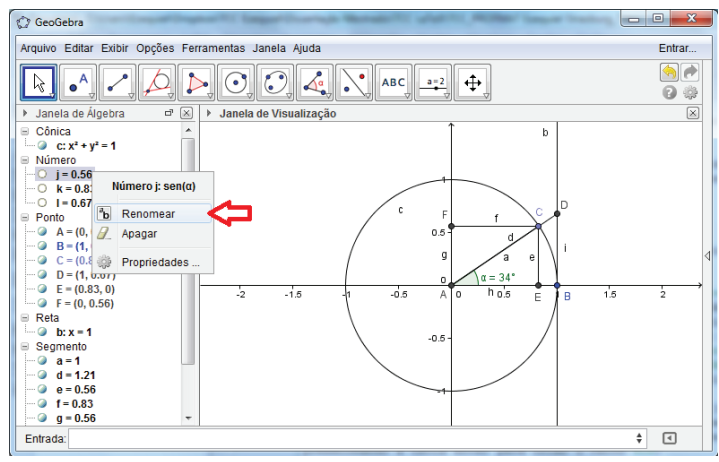

Figura 17: Primeiro passo para renomear objeto

Embora o círculo trigonométrico 1a já possa ser usado, recomenda-se organizar a figura na janela de visualização com os itens facultativos, a seguir:

15. Caso os rótulos (nomes de pontos, retas, segmentos de reta, círculo, etc) apareçam na janela de 


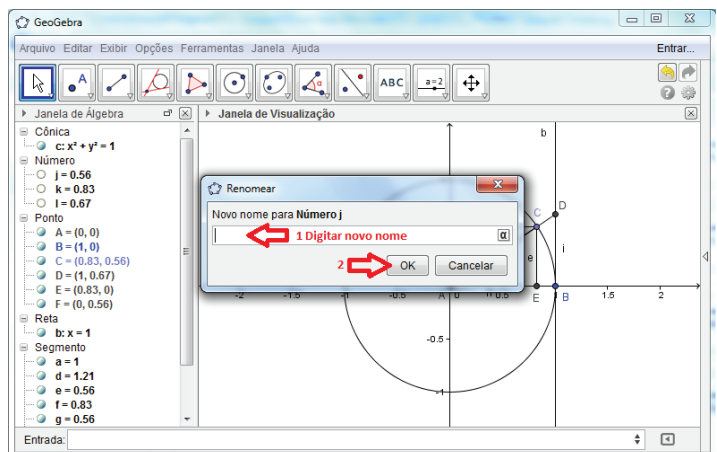

Figura 18: Segundo passo para renomear objeto

visualização, ocultar esses rótulos: barra de recursos, clicar no botão 12, depois clicar na opção exibir/esconder rótulo, conforme a Figura 19. Na janela de álgebra, clicar em $a, b, c, d, e, f, g, h$ e $i$, ocultando esses rótulos na figura;

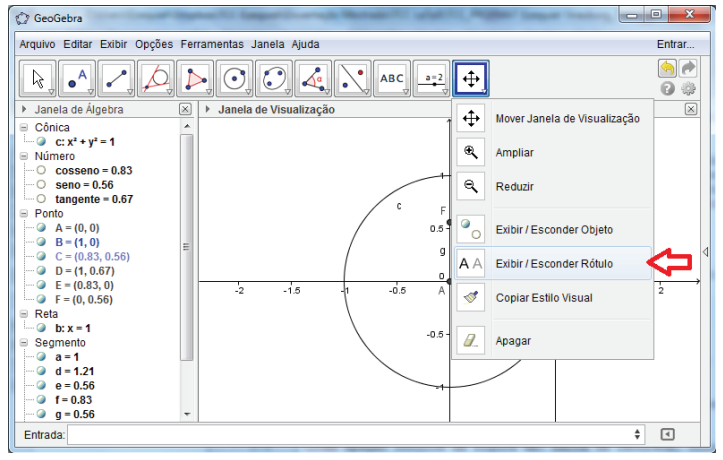

Figura 19: Exibir, ou esconder, rótulo na figura

16. Para aumentar a espessura do círculo $c$ e dos segmentos de reta $\overline{A F}, \overline{A E}$ e $\overline{B D}$, veja as Figuras 20 e 21;

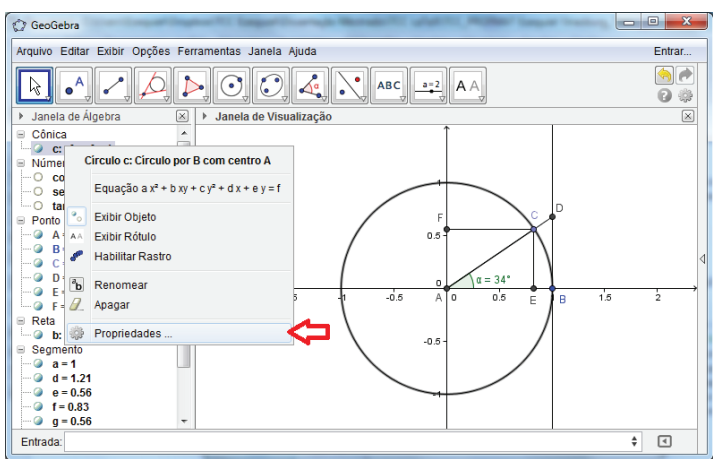

Figura 20: Propriedades

17. É possível alterar as cores dos segmentos de reta $\overline{A F}, \overline{A E}$ e $\overline{B D}$, conforme a Figura 22. Se desejar

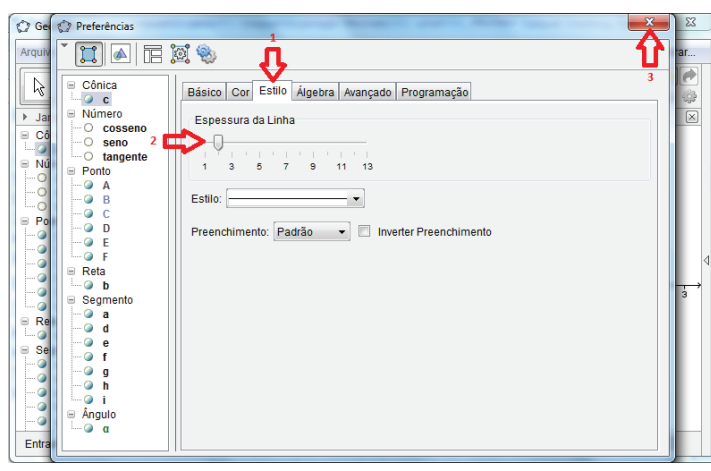

Figura 21: Aumentar espessura da linha

exibir malhas na janela de visualização veja Figura 23;

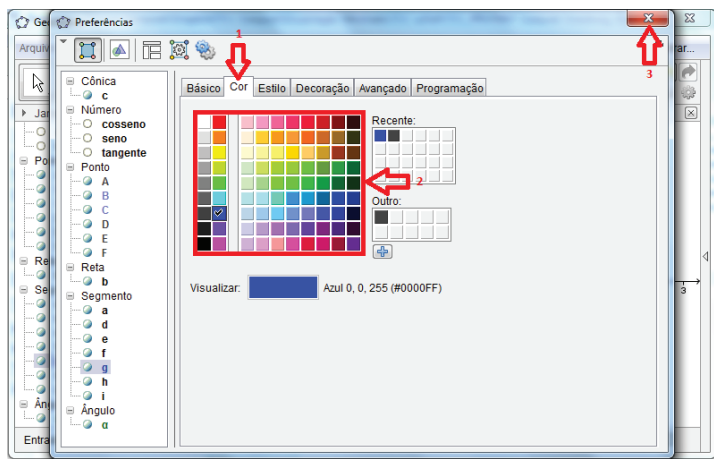

Figura 22: Alterar cor

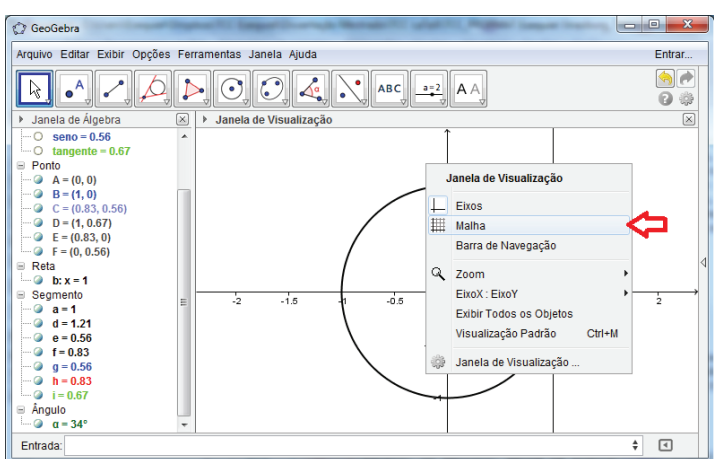

Figura 23: Exibir, ou excluir, malha na figura

Com o círculo trigonométrico 1a, é possível alterar a medida do ângulo $\alpha$, na barra de recursos, clicar no botão 1, depois clicar na opção mover. Na janela de visualização arrastar o ponto $C$ sobre o círculo $c$.

\subsection{Construção do círculo trigonométrico 1b}

Para iniciar a construção do círculo trigonométrico $1 b$, seguir os passos de 1 a 4 do círculo trigonométrico 1a e 
os passos a seguir:

1. Criar um ângulo qualquer: barra de entrada, digitar um ângulo qualquer, com exceção dos ângulos $90^{\circ}$ e $270^{\circ}$, por exemplo $\alpha=34^{\circ}$. Para digitar $\alpha$ e o símbolo "o" na barra de entrada, basta clicar no botão ao lado direito da barra de entrada e depois clicar na opção $\alpha$ e "o". Conforme a Figura 24;

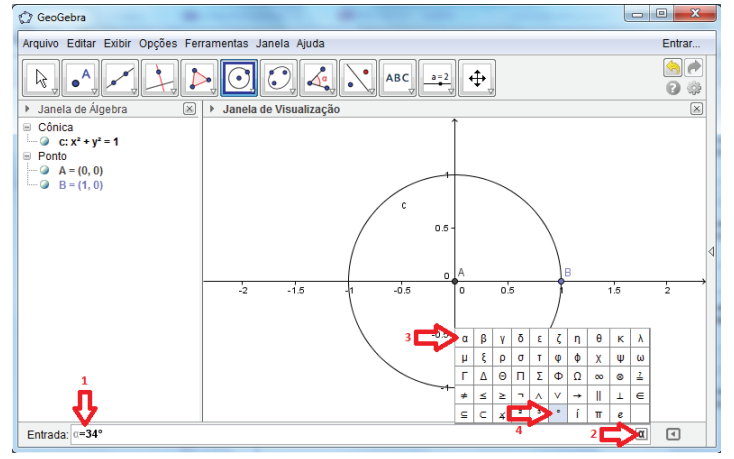

Figura 24: Digitar ângulo

2. Criar o ângulo $\beta$ em: barra de recursos, clicar no botão 8 , depois clicar na opção ângulo com amplitude fixa, conforme a Figura 25. Na janela de visualização, clicar no ponto $B$, depois clicar no ponto $A$, e abrirá uma janela, em seguida digitar $\alpha$, depois selecionar a opção sentido anti-horário, e por fim clicar em OK, conforme a Figura 26, criando o ponto $B^{\prime}$ e o ângulo $\beta=\alpha$. Para digitar $\alpha$ na barra dessa janela, basta clicar no botão ao lado direito dessa barra e depois clicar na opção $\alpha$;

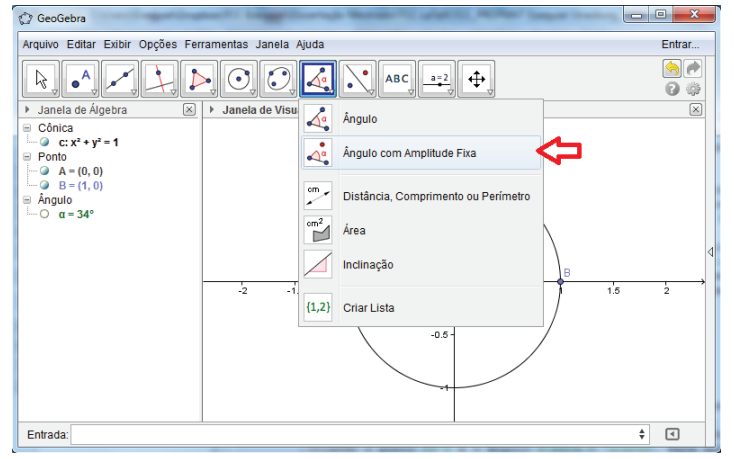

Figura 25: Primeiro passo para criar ângulo com amplitude fixa

3. Renomear o ângulo $\beta \operatorname{como} \theta$, veja Figura 27;

4. Renomear o ponto $B^{\prime}$ como $C$;

5. Traçar o segmento de reta $\overline{A C}$;

6. Traçar a reta tangente ao círculo $c$, pelo ponto $(1,0)$ criando a reta $b$;

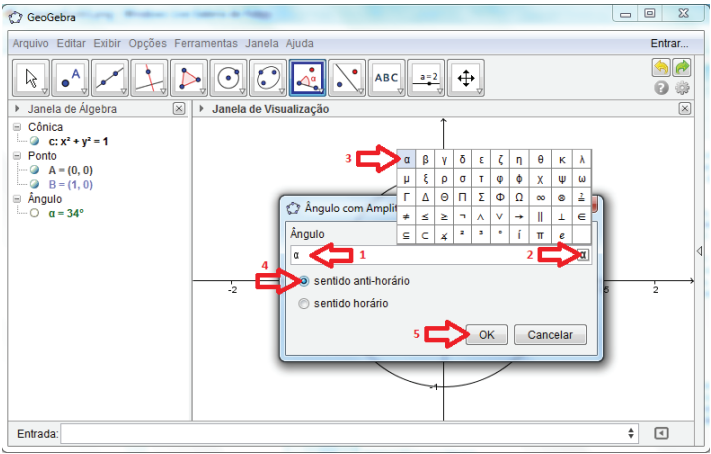

Figura 26: Segundo passo para criar ângulo com amplitude fixa

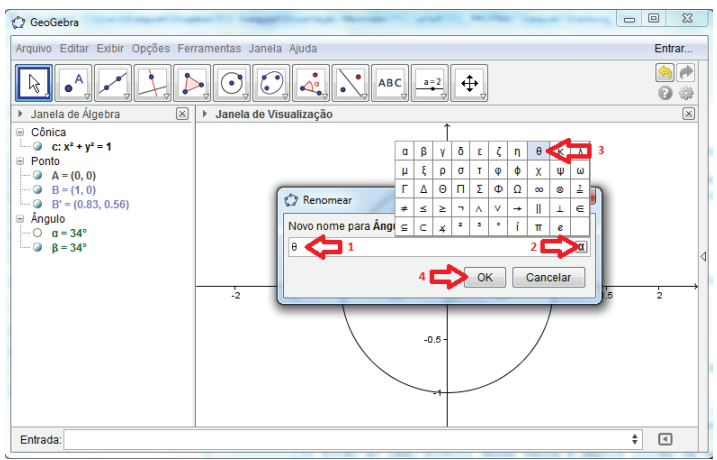

Figura 27: Renomear ângulo

\section{Observação:}

(a) O software GeoGebra não criará a reta tangente ao clicar nos pontos $B$ e $C$, por esse motivo o ponto $C$ não pode ser escolhido para essa construção.

7. Criar o ponto $D$ que contém a tangente de $\alpha$ na coordenada $y$, sobre a reta $b$, em: barra de entrada, digitar o ponto $(1, \operatorname{tg}(\alpha))$;

8. Criar o ponto $E$ que contém o cosseno de $\alpha$ na coordenada $x$, sobre o eixo $x$, em: barra de entrada, digitar o ponto $(\cos (\alpha), 0)$;

9. Criar o ponto $F$ que contém o seno de $\alpha$ na coordenada $y$, sobre o eixo $y$, em: barra de entrada, digitar o ponto $(0, \operatorname{sen}(\alpha))$;

10. Traçar os segmentos de reta $d=\overline{A D}, e=\overline{C E}$, $f=\overline{C F}, g=\overline{A F}, h=\overline{A E}$ e $i=\overline{B D}$;

11. Escrever os valores de seno, cosseno e tangente na janela de álgebra e renomear os valores, conforme os passos 13 e 14 da construção do círculo trigonométrico 1a; 
Embora o círculo trigonométrico $1 \mathrm{~b}$ já possa ser usado, recomenda-se organizar a figura na janela de visualização com os itens facultativos, a seguir:

12. Caso os rótulos (nomes de pontos, retas, segmentos de reta, círculo, etc) apareçam na janela de visualização, é possível esconder esses rótulos, aumentar a espessura do círculo, mudar cores e exibir malhar, passos que estão descritos no círculo trigonométrico 1a. Além disso, é possível mudar um rótulo de posição.

Com o círculo trigonométrico $1 \mathrm{~b}$, é possível alterar a medida do ângulo $\alpha$, na barra de entrada, digitar o ângulo (por exemplo: $\alpha=40^{\circ}$ ), e pressionar a tecla enter, conforme a Figura 24.

Observações:

1. Nas construções dos círculos trigonométricos 1a e $1 \mathrm{~b}$, o professor pode modificar as figuras conforme desejar, aumentando ou diminuindo a espessura das linhas, e modificando as cores das linhas, dos pontos e dos rótulos;

2. O que diferencia o círculo trigonométrico 1a do $1 \mathrm{~b}$ é a forma como se modifica o ângulo. O primeiro ficará com o ângulo nomeado $\alpha$, enquanto o segundo $\theta$;

3. Com os círculos trigonométricos $1 \mathrm{a}$ e $1 \mathrm{~b}$, o professor tem uma interessante ferramenta para trabalhar as relações trigonométricas envolvendo seno, cosseno e tangente;

4. Para modificar o ângulo no círculo trigonométrico 1a arrasta-se o ponto $C$ pelo círculo e para modificar o ângulo no círculo trigonométrico $1 \mathrm{~b}$ digitase o ângulo na barra de entrada. Dessa forma, quando o professor tem o objetivo de mostrar aos alunos os valores de seno, cosseno e tangente de um ângulo $\alpha$ e a forma como acontece a variação desses valores em relação ao ângulo $\alpha$, é mais conveniente usar o círculo trigonométrico 1a, por ser mais dinâmico. Mas quando se deseja encontrar os valores de seno, cosseno e tangente, para um valor de $\alpha$ específico, é mais conveniente usar o círculo trigonométrico $1 \mathrm{~b}$. Uma vantagem do círculo trigonométrico 1a é que se pode fazer o ângulo $\alpha$ aumentar automaticamente através de uma animação. Na janela de álgebra, clicar com o botão direito do mouse no ponto $C$, e abrirá uma janela, em seguida, deve-se clicar no botão animar, conforme a Figura 28. Repetir o processo caso se queira parar a animação.

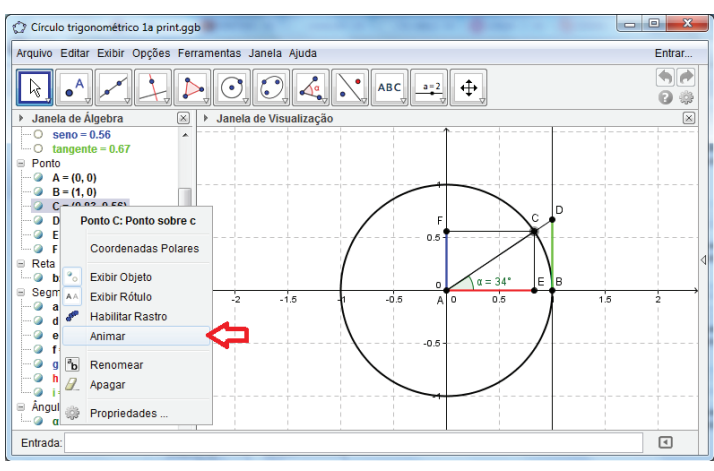

Figura 28: Animar figura

\section{Círculo trigonométrico 2: secante, cossecante e cotangente}

O círculo trigonométrico 2 apresenta os valores de secante, cossecante e cotangente de um ângulo $\alpha$ e esta seção apresenta duas construções para o círculo trigonométrico 2, que se diferem na forma como se altera o ângulo. Estas construções serão chamadas de círculo trigonométrico $2 \mathrm{a}$ e círculo trigonométrico $2 \mathrm{~b}$.

\subsection{Construção do círculo trigonométrico 2a}

1. Seguir os mesmos passos das construções do círculo trigonométrico 1a para verificar se os eixos $x$ e $y$ estão expostos na janela de visualização. Reposicionar a figura. Ajustar o tamanho da figura. Criar o círculo $c$ de raio unitário com centro em $A=(0,0)$ passando por $B=(0,1)$;

2. Criar um ponto $C$ qualquer sobre o círculo $c$, com as mesmas restrições feitas durante a construção do círculo trigonométrico 1a. Além disso, traçar o segmento de reta $\overline{A C}$ e construir o ângulo $\alpha$ exatamente como fizemos em $1 \mathrm{a}$.

3. Traçar a reta tangente ao círculo $c$, pelo ponto $(0,1)$. Na janela de visualização, clicar no ponto $B$, e depois clicar em qualquer outro ponto do círculo $c$, diferente de $C$, criando a reta $b$;

\section{Observação:}

(a) O software GeoGebra não criará a reta tangente ao clicar nos pontos $B$ e $C$, por esse motivo o ponto $C$ não pode ser escolhido para essa construção.

4. Criar os pontos $D=(\operatorname{cotg}(\alpha), 1), E=(\sec (\alpha), 0)$, $F=(0, \operatorname{cosec}(\alpha))$ e os segmentos de reta $d=\overline{A D}$, $e=\overline{E F}, f=\overline{A E}, g=\overline{A F}$ e $h=\overline{B D}$;

5. Escrever os valores de secante, cossecante e cotangente na janela de álgebra, da seguinte forma: 
digitar na barra de entrada $\sec (\alpha)$, conforme a Figura 29, e pressionar a tecla enter, criando o valor $i$. Depois repetir o processo digitando $\operatorname{cosec}(\alpha)$ e pressionando a tecla enter para criar o valor $j$, e por fim, digitando $\operatorname{cotg}(\alpha)$ e pressionando a tecla enter para criar o valor $k$;

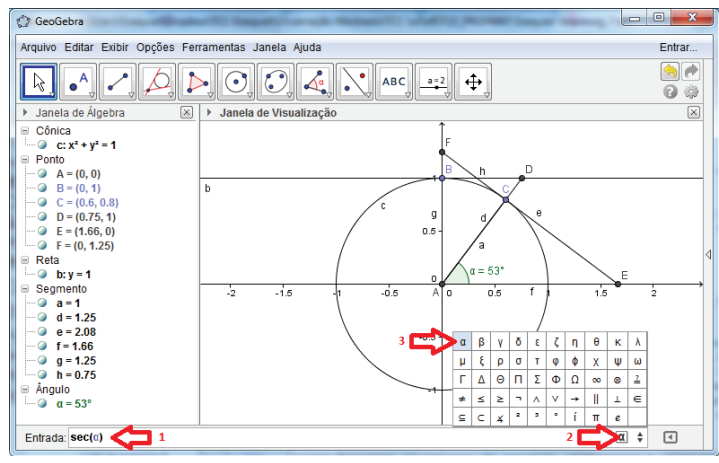

Figura 29: Criar o valor de secante na janela de álgebra

6. Renomear os valores $i, j$ e $k$ respectivamente de secante, cossecante, e cotangente.

Embora o círculo trigonométrico 2a já possa ser usado, recomenda-se organizar a figura na janela de visualização com os itens facultativos como esconder rótulos, aumentar espessura, mudar cores e exibir malha.

Com o círculo trigonométrico 2a, é possível alterar a medida do ângulo $\alpha$, na barra de recursos, clicar no botão 1, depois clicar na opção mover. Na janela de visualização arrastar o ponto $C$ sobre o círculo $c$.

\subsection{Construção do círculo trigonométrico $2 b$}

1. Seguir os mesmos passos das construções do círculo trigonométrico 1a para verificar se os eixos $x$ e $y$ estão expostos na janela de visualização. Reposicionar a figura. Ajustar o tamanho da figura. Criar o círculo $c$ de raio unitário com centro em $A=(0,0)$ passando por $B=(0,1)$;

2. Criar um ângulo qualquer em: barra de entrada, digitar um ângulo qualquer, com exceção dos ângulos $0^{\circ}, 90^{\circ}, 180^{\circ}$ e $270^{\circ}$, por exemplo $\alpha=53^{\circ}$, e pressionar a tecla enter, criando o valor $\alpha=53^{\circ}$ na janela de álgebra. Para digitar $\alpha$ e o símbolo "o"na barra de entrada, basta clicar no botão ao lado direito da barra de entrada e depois clicar na opção $\alpha$ e no símbolo "०";

\section{Observações:}

(a) Não podem ser escolhidos os ângulos $0^{\circ}, 90^{\circ}$, $180^{\circ}$ e $270^{\circ}$ pelo fato da secante de um ângulo não estar definida para os ângulos $90^{\circ}$ e $270^{\circ}$ e a cossecante e a cotangente de um ângulo não estarem definidas para os ângulos de $0^{\circ}$ e $180^{\circ}$;

(b) Evite escolher um ângulo com pouca diferença para os ângulos onde a secante, cossecante e cotangente não estão definidas, pois isso pode dificultar a construção da figura.

3. Criar um novo ponto no círculo, na barra de recursos, clicar no botão 2, depois clicar na opção ponto, conforme a Figura 9. Na janela de visualização, clicar ponto $(1,0)$, criando assim o ponto $C$;

4. Renomear o ponto $C$ para $X$, conforme a Figura 18;

5. Criar o ângulo $\beta$ em: barra de recursos, clicar no botão 8, depois clicar na opção ângulo com amplitude fixa, conforme a Figura 25. Na janela de visualização, clicar no ponto $X$, depois clicar no ponto $A$, e abrirá uma janela, em seguida, digitar $\alpha$, depois selecionar a opção sentido anti-horário, e por fim clicar em OK, conforme a Figura 26, criando o ponto $X^{\prime}$ e o ângulo $\beta=\alpha$. Para digitar $\alpha$ na barra dessa janela, basta clicar no botão ao lado direito dessa barra e depois clicar na opção $\alpha$;

6. Renomear o ângulo $\beta \operatorname{como} \theta$ e renomear o ponto $X^{\prime}$ como $C$, conforme a Figura 18;

7. Traçar o segmento de reta $\overline{A C}$ em: barra de recursos, clicar no botão 3, depois clicar na opção segmento, conforme a Figura 10. Na janela de visualização, clicar no ponto $A(0,0)$ e depois clicar no ponto $C$, criando o segmento de reta $a=\overline{A C}$;

8. Traçar a reta tangente ao círculo $c$, pelo ponto $(0,1)$ em: barra de recursos, clicar no botão 4, depois clicar na opção reta tangente, conforme a Figura 12. Na janela de visualização, clicar no ponto $B, \mathrm{e}$ depois clicar em qualquer outro ponto do círculo $c$, diferente de $C$, criando a reta $b$;

\section{Observação:}

(a) O software GeoGebra não criará a reta tangente ao clicar nos pontos $B$ e $C$, por esse motivo o ponto $C$ não pode ser escolhido para essa construção.

9. Criar os pontos $D=(\operatorname{cotg}(\alpha), 1), E=(\sec (\alpha), 0)$, $F=(0, \operatorname{cosec}(\alpha))$ e traçar os segmentos de reta $d=\overline{A D}, e=\overline{E F}, f=\overline{A E}, g=\overline{A F}$ e $h=\overline{B D}$;

10. Escrever os valores de secante, cossecante e cotangente na janela de álgebra, da seguinte forma: digitar na barra de entrada $\sec (\alpha)$ e pressionar a tecla enter, criando o valor $i$. Depois repetir o processo digitando $\operatorname{cosec}(\alpha)$ e pressionando a tecla enter para criar o valor $j$, e por fim, digitando 
$\operatorname{cotg}(\alpha)$ e pressionando a tecla enter para criar o valor $k$;

11. Renomear os valores $i, j$ e $k$ como secante, cossecante e cotangente respectivamente;

12. Ocultar o ponto $X$.

Embora o círculo trigonométrico $2 b$ já possa ser usado, recomenda-se organizar a figura na janela de visualização com os itens facultativos, como ocultar rótulos, aumentar espessura, mudar cores e exibir malha.

Com o círculo trigonométrico $2 \mathrm{~b}$, é possível alterar a medida do ângulo $\alpha$ em: barra de entrada, digitar o ângulo (por exemplo: $\alpha=40^{\circ}$ ), e pressionar a tecla enter, conforme a Figura 24.

Observações:

1. Nas construções anteriores, o professor pode modificar as figuras conforme desejar, aumentando ou diminuindo a espessura das linhas, e modificando as cores das linhas, dos pontos e dos rótulos.

2. A única diferença, na janela de visualização, entre o círculo trigonométrico 2a e o círculo trigonométrico $2 \mathrm{~b}$ é que um ficará com o ângulo nomeado $\alpha$, enquanto o outro ficará com o ângulo nomeado $\theta$.

3. Com os círculos trigonométricos $2 \mathrm{a}$ e $2 \mathrm{~b}$, o professor tem uma interessante ferramenta para trabalharas relações trigonométricas envolvendo secante, cossecante e cotangente. O que diferencia o círculo trigonométrico $2 \mathrm{a}$ do círculo trigonométrico $2 \mathrm{~b}$ é a forma como se modifica o ângulo.

4. Para modificar o ângulo no círculo trigonométrico 2 a arrasta-se o ponto $C$ pelo círculo, e para modificar o ângulo no círculo trigonométrico $2 \mathrm{~b}$ digitase o ângulo na barra de entrada. Dessa forma, quando o professor tem o objetivo de mostrar aos alunos os valores de secante, cossecante e cotangente de um ângulo $\alpha$, e a forma como acontece a variação desses valores em relação ao ângulo $\alpha$, é mais conveniente usar o círculo trigonométrico 2a, por ser mais dinâmico. Mas quando se deseja encontrar os valores de secante, cossecante e cotangente de $\alpha$ específico, é mais conveniente usar o círculo trigonométrico $2 \mathrm{~b}$. Uma vantagem do círculo trigonométrico 2a é que se pode fazer o ângulo $\alpha$ aumentar automaticamente através de uma animação, da seguinte forma: na janela de álgebra, clicar com o botão direito do mouse no ponto $C$, e abrirá uma janela, deve-se clicar no botão animar, conforme a Figura 28. Repetir o processo caso se queira parar a animação.
É possível colocar todas as informações em um só círculo, ou também colocar as informações separadamente, de acordo com a necessidade e da proposta em sala de aula.

Na Figura 30, tem-se um círculo trigonométrico completo (mesclando as construções feitas), com as informações de seno, cosseno, tangente, secante, cossecante e cotangente.

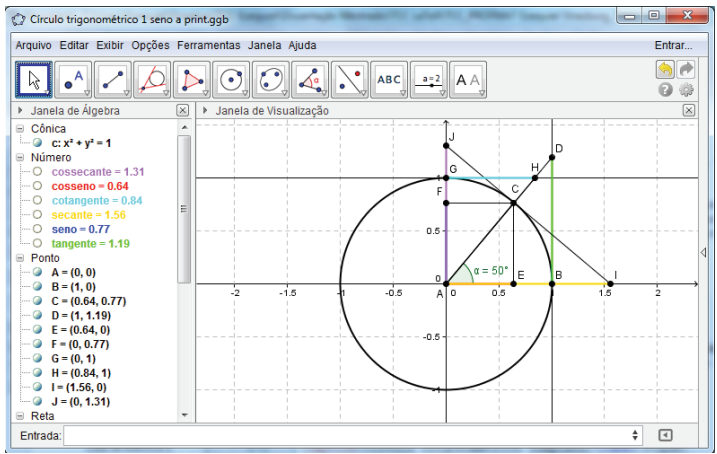

Figura 30: Círculo trigonométrico completo

Ao longo do trabalho, usaremos os círculos trigonométricos 1 e 2 , seguindo rigorosamente a nomenclatura utilizada na construção conforme o passo-a-passo.

\subsection{Atividades propostas}

Trigonometria e círculo trigonométrico estão diretamente associados, porém a maioria dos livros didáticos do $9^{\circ}$ ano do Ensino Fundamental trazem uma proposta de explicar trigonometria sem fazer menção à existência do círculo trigonométrico. Através do círculo trigonométrico conclui-se não somente o que são os valores de seno, cosseno, tangente, secante, cossecante e cotangente de um ângulo, mas também de onde surgem, e porque levam esses nomes. A maioria das relações trigonométricas podem ser concluídas usando o círculo trigonométrico e fazendo uso de semelhança de triângulos, pois no círculo se encontram absolutamente todos os triângulos possíveis com cateto ou hipotenusa unitários. Portanto, uma boa parte das relações trigonométricas consiste em comparar um triângulo retângulo qualquer à outro triângulo semelhante do círculo trigonométrico, que tem cateto ou hipotenusa unitários.

A seguir apresentam-se algumas atividades com o uso do software GeoGebra e as construções dos círculos trigonométricos, com intuito de levar os alunos às conclusões das relações trigonométricas. Antes de mais nada, é importante que os alunos tenham estudado semelhança e congruência de triângulos, proporção, Teorema de Tales, Teorema de Pitágoras, soma dos ângulos internos dos triângulo, conversão de unidades de medida do ângulo, pontos no plano cartesiano. 
Atividade 7.1 (Explorando o círculo trigonométrico no software GeoGebra). Esta atividade tem o propósito de mostrar como encontrar os valores de seno, cosseno, tangente, secante, cossecante, e cotangente, de um ângulo $\alpha$ no círculo trigonométrico. Nesta atividade usaremos uma das construções feitas na seção 7 .

O uso do círculo trigonométrico no software GeoGebra, torna-se interessante pois através dele é possível encontrar os valores de seno, cosseno, tangente, secante, cossecante e cotangente de um ângulo $\alpha$, podendo ser visualizada a representação geométrica. O professor pode realizar essas construções com régua e compasso, mas a vantagem da construção no software GeoGebra é a precisão e dinamismo.

Objetivos: Estimular os alunos ao uso de recursos tecnológicos na aprendizagem; mostrar aos alunos a representação geométrica dos valores de seno, cosseno, tangente, secante, cossecante e cotangente de um âgulo $\alpha$ e explicar o motivo pelo qual se utilizam as palavras tangente e secante.

Pré-requisitos: Semelhança e congruência de triângulos; Retas paralelas cortadas por transversal; Soma dos ângulos internos de um triângulo; Pontos no plano cartesiano e conhecimentos mínimos sobre utilização do software GeoGebra.

Material necessário: Equipamento que tenha instalado o software GeoGebra, além do material escolar usual.

Tempo necessário: 2 horas/aula.

Dicas ao professor:

1. No círculo trigonométrico 1: o seno do ângulo $\alpha$, que podemos abreviar por sen $(\alpha)$ é a coordenada $y$ do ponto $F$; o cosseno do ângulo $\alpha$, que podemos abreviar por $\cos (\alpha)$ é a coordenada $x$ do ponto $E \mathrm{e}$ a tangente do ângulo $\alpha$, que podemos abreviar por $\operatorname{tg}(\alpha)$ é a coordenada $y$ do ponto $D$. Portanto, temse os pontos $C=(\cos (\alpha), \operatorname{sen}(\alpha))$ e $D=(1, \operatorname{tg}(\alpha))$;

2. No círculo trigonométrico 2: a secante do ângulo $\alpha$, que podemos abreviar por $\sec (\alpha)$ é a coordenada $x$ do ponto $E$; a cossecante do ângulo $\alpha$, que podemos abreviar por $\operatorname{cosec}(\alpha)$ é a coordenada $y$ do ponto $F$ e a cotangente de um ângulo $\alpha$, que podemos abreviar por $\operatorname{cotg}(\alpha)$ é a coordenada $x$ do ponto $D$. Portanto, tem-se os pontos $E=$ $(\sec (\alpha), 0), F=(0, \operatorname{cosec}(\alpha))$ e $D=(\operatorname{cotg}(\alpha), 1)$.

Exercício 2. De posse do círculo trigonométrico 1, construído no software GeoGebra, faça as atividades a seguir:

a) No círculo trigonométrico $1 a$, faça o ângulo $\alpha$ variar automaticamente através de uma animação. Para fazer esta animação deve-se clicar com o botão direito do mouse no ponto $C$, da janela de álgebra, ou da janela de visualização, e abrirá uma janela, em seguida deve-se clicar na opção animar; b) Observando a janela de álgebra, escreva os valores que seno, cosseno e tangente do ângulo $\alpha$ assumem quando: $\alpha=0^{\circ}, \alpha=90^{\circ}, \alpha=180^{\circ}$ e $\alpha=270^{\circ}$;

c) Observando a janela de álgebra, escreva os valores que seno, cosseno e tangente do ângulo $\alpha$ assumem em cada quadrante: $0^{\circ}<\alpha<90^{\circ}$ ( $1^{\circ}$ quadrante), $90^{\circ}<\alpha<$ $180^{\circ}$ ( $2^{\circ}$ quadrante), $180^{\circ}<\alpha<270^{\circ}$ ( $3^{\circ}$ quadrante) e $270^{\circ}<\alpha<360^{\circ}$ (4 $4^{\circ}$ quadrante);

d) Compare os valores de seno, cosseno e tangente do ângulo $\alpha$ com os valores das coordenadas dos pontos $C$ e $D$.

Exercício 3. De posse do círculo trigonométrico 2, construído no software GeoGebra, faça as atividades a seguir:

a) No círculo trigonométrico $2 a$, faça o ângulo $\alpha$ variar automaticamente através de uma animação. Para fazer esta animação deve-se clicar com o botão direito do mouse no ponto $C$, da janela de álgebra, ou da janela de visualização, e abrirá uma janela, em seguida deve-se clicar na opção animar.

b) Observando a janela de álgebra, escreva os valores que secante, cossecante e cotangente do ângulo $\alpha$ assumem quando: $\alpha=0^{\circ}, \alpha=90^{\circ}, \alpha=180^{\circ}$ e $\alpha=270^{\circ}$;

c) Observando a janela de álgebra, escreva os valores que secante, cossecante e cotangente do ângulo $\alpha$ assumem em cada quadrante: $0^{\circ}<\alpha<90^{\circ}$ (1 ${ }^{\circ}$ quadrante), $90^{\circ}<\alpha<180^{\circ}$ ( $2^{\circ}$ quadrante), $180^{\circ}<\alpha<270^{\circ}$ (3 quadrante) e $270^{\circ}<\alpha<360^{\circ}$ ( $4^{\circ}$ quadrante);

d) Compare os valores de secante, cossecante e cotangente do ângulo $\alpha$ com os valores das coordenadas dos pontos $D, E$ e $F$.

Exercício 4. De posse do círculo trigonométrico 2, construído no software GeoGebra, escolha um valor para $\alpha$ entre $0^{\circ}$ e $90^{\circ}$. Em seguida, demonstre que os triângulos $A C E, A C F, A B D$ e $A E F$ são semelhantes e demonstre que os triângulos $A C F$ e $A B D$ também são congruentes. Observação: $\mathrm{O}$ segmento $\overline{A D}$ é perpendicular ao segmento $\overline{E F}$.

\section{Solução da Atividade 7.1: \\ Exercício 2}

a) Para fazer animação é preciso: na janela de álgebra ou na janela de visualização, clicar com o botão direito do mouse no ponto $C$, e abrirá uma janela. Deve-se clicar no botão animar. Repetir o processo caso se queira parar a animação.

Para resolver os itens (b) e (c) do exercício 2, podese obervar os valores encontrados na janela de álgebra, conforme a Figura 31.

b) Observando a janela de álgebra, podemos encontrar os seguintes valores de $\operatorname{sen}(\alpha), \cos (\alpha)$ e $\operatorname{tg}(\alpha)$ para $\alpha=0^{\circ}, \alpha=90^{\circ}, \alpha=180^{\circ}$ e $\alpha=270^{\circ}$, conforme a Tabela 1 : 


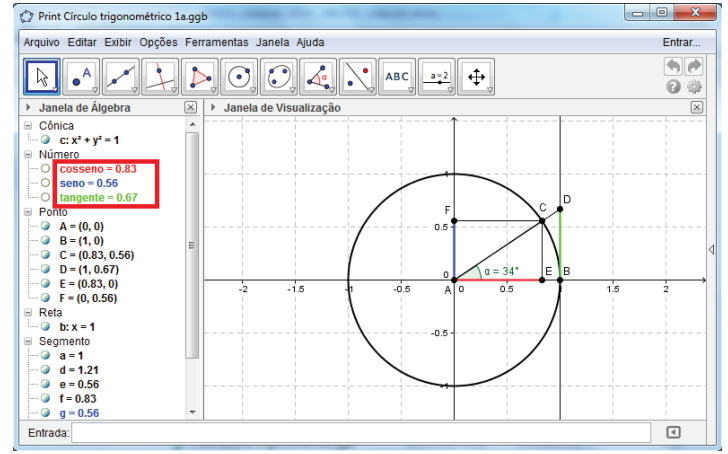

Figura 31: Atividade 7.1, exercício 2 - Solução

Tabela 1: Valores de $\operatorname{sen}(\alpha), \cos (\alpha)$ e $\operatorname{tg}(\alpha)$ para $\alpha=$ $0^{\circ}, 90^{\circ}, 180^{\circ}, 270^{\circ}$

\begin{tabular}{lllll}
\hline & $\alpha=0^{\circ}$ & $\alpha=90^{\circ}$ & $\alpha=180^{\circ}$ & $\alpha=270^{\circ}$ \\
\hline $\operatorname{sen}(\alpha)$ & 0 & 1 & 0 & -1 \\
$\cos (\alpha)$ & 1 & 0 & -1 & 0 \\
$\operatorname{tg}(\alpha)$ & 0 & $\nexists$ & 0 & $\nexists$ \\
\hline
\end{tabular}

c) Observando a janela de álgebra, podemos encontrar os seguintes valores para $\operatorname{sen}(\alpha), \cos (\alpha)$ e $\operatorname{tg}(\alpha)$ em cada quadrante, conforme a Tabela 2:

Tabela 2: Valores de $\operatorname{sen}(\alpha), \cos (\alpha)$ e $\operatorname{tg}(\alpha)$ para cada quadrante

\begin{tabular}{lllll}
\hline & $1^{\mathrm{O}}$ & $2^{\mathrm{o}}$ & $3^{\mathrm{o}}$ & $4^{\mathrm{o}}$ \\
\hline $\operatorname{sen}(\alpha)$ & $(0,1)$ & $(0,1)$ & $(-1,0)$ & $(-1,0)$ \\
$\cos (\alpha)$ & $(0,1)$ & $(-1,0)$ & $(-1,0)$ & $(0,1)$ \\
$\operatorname{tg}(\alpha)$ & $(0,+\infty)$ & $(-\infty, 0)$ & $(0,+\infty)$ & $(-\infty, 0)$ \\
\hline
\end{tabular}

d) Comparando os valores de seno, cosseno e tangente do ângulo $\alpha$ com os valores das coordenadas dos pontos $C$ e $D$, pode-se concluir que: $\operatorname{sen}(\alpha)$ é a coordenada $y$ do ponto $C ; \cos (\alpha)$ é a coordenada $x$ do ponto $C$ e $\operatorname{tg}(\alpha)$ é a coordenada $y$ do ponto $D$.

Importante: Diga aos alunos que embora os livros didáticos do $9^{\circ}$ ano no Ensino Fundamental frequentemente definem a tangente de um ângulo agudo como a razão entre a medida do cateto oposto e a medida do cateto adjacente ao ângulo, em um triângulo retângulo, a tangente de um ângulo qualquer leva esse nome por ser o valor da coordenada $y$ do ponto $D$ que pertence à reta tangente ao círculo trigonométrico no ponto $(1,0)$, conforme o círculo trigonométrico 1.

\section{Exercício 3}

a) Para fazer animação é preciso: na janela de álgebra, clicar com o botão direito do mouse no ponto $C$, e abrirá uma janela. Deve-se clicar no botão animar. Repetir o processo caso se queira parar a animação.
Para resolver os itens (b) e (c) do exercício 3, podese obervar os valores encontrados na janela de álgebra, como foi feito no exercício 2.

b) Observando a janela de álgebra, podemos encontrar os seguintes valores de $\sec (\alpha), \operatorname{cosec}(\alpha)$ e $\operatorname{cotg}(\alpha)$ para $\alpha=0^{\circ}, \alpha=90^{\circ}, \alpha=180^{\circ}$ e $\alpha=270^{\circ}$, conforme a Tabela 3:

Tabela 3: Valores de $\sec (\alpha), \operatorname{cosec}(\alpha)$ e $\operatorname{cotg}(\alpha)$ para $\alpha=0^{\circ}, 90^{\circ}, 180^{\circ}, 270^{\circ}$

\begin{tabular}{lllll}
\hline & $\alpha=0^{\circ}$ & $\alpha=90^{\circ}$ & $\alpha=180^{\circ}$ & $\alpha=270^{\circ}$ \\
\hline $\sec (\alpha)$ & 1 & $\nexists$ & -1 & $\nexists$ \\
$\operatorname{cosec}(\alpha)$ & $\nexists$ & 1 & $\nexists$ & -1 \\
$\operatorname{cotg}(\alpha)$ & $\nexists$ & 0 & $\nexists$ & 0 \\
\hline
\end{tabular}

c) Observando a janela de álgebra, podemos encontrar os seguintes valores para $\sec (\alpha), \operatorname{cosec}(\alpha)$ e $\operatorname{cotg}(\alpha)$ em cada quadrante, conforme a Tabela 4:

d) Comparando os valores de secante, cossecante e cotangente do ângulo $\alpha$ com os valores das coordenadas dos pontos $D, E$ e $F$, pode-se concluir que: $\sec (\alpha)$ é a coordenada $x$ do ponto $E ; \operatorname{cosec}(\alpha)$ é a coordenada $y$ do ponto $F$ e $\operatorname{cotg}(\alpha)$ é a coordenada $x$ do ponto $D$.

Importante: Diga aos alunos que a palavra "secante "é utilizada, pois a secante de um ângulo $\alpha$ é o valor da coordenada $x$ do ponto $E$ no círculo trigonométrico 2 e o ponto $E$ pertence à reta $\overleftrightarrow{A E}$ que é secante por intersectar o círculo $c$ em dois pontos.

\section{Exercício 4}

Primeiramente escolha um ângulo $\alpha$ agudo no círculo trigonométrico 2.

Demonstração de que o triângulo $A C E$ é semelhante ao triângulo $A C F$ :

Os triângulos $A C E$ e $A C F$ são retângulos, pois como os segmentos $\overline{A D}$ e $\overline{E F}$ são perpendiculares, os ângulos $A \widehat{C} E$ e $F \widehat{C} A$ são retos. Como a soma das medidas dos ângulos internos de um triângulo é igual a $180^{\circ}$ temse que o ângulo $C \widehat{E} A$ mede $90^{\circ}-\alpha$ (ou seja, o ângulo $C \widehat{E} A$ é complementar ao ângulo $\alpha$ ). Como o ângulo $C \widehat{A} F$ também é complementar ao ângulo $\alpha$ tem-se que os ângulos $C \widehat{E} A$ e $C \widehat{A} F$ são congruentes. Portanto, o triângulo $A C E$ é semelhante ao triângulo $A C F$ por $\mathrm{AA}$ (possuem dois ângulos correspondentes congruentes).

Demonstração de que o triângulo $A C F$ é semelhante e congruente ao triângulo $A B D$ :

O triângulo $A B D$ é retângulo, pois o ângulo $A \widehat{B} D$ é reto, e o triângulo $A C F$ é retângulo, conforme foi visto anteriormente. Tem-se que os ângulos $B \widehat{D} A$ e $\alpha$ são congruentes pois são ângulos alternos internos. Então o 
Tabela 4: Valores de $\sec (\alpha), \operatorname{cosec}(\alpha)$ e $\operatorname{cotg}(\alpha)$ para cada quadrante

\begin{tabular}{lllll}
\hline & $1^{\mathrm{o}}$ & $2^{\mathrm{o}}$ & $3^{\mathrm{o}}$ & $4^{\mathrm{o}}$ \\
\hline $\sec (\alpha)$ & $(1,+\infty)$ & $(-\infty,-1)$ & $(-\infty,-1)$ & $(1,+\infty)$ \\
$\operatorname{cosec}(\alpha)$ & $(1,+\infty)$ & $(1,+\infty)$ & $(-\infty,-1)$ & $(-\infty,-1)$ \\
$\operatorname{cotg}(\alpha)$ & $(0,+\infty)$ & $(-\infty, 0)$ & $(0,+\infty)$ & $(-\infty, 0)$ \\
\hline
\end{tabular}

triângulo $A C F$ é semelhante ao triângulo $A B D$ por AA (possuem dois ângulos correspondentes congruentes). Além disso, pode-se perceber que esses triângulos tem os lados correspondentes $\overline{A C}$ e $\overline{A B}$ com medida unitária. Portanto, o triângulo $A C F$ é congruente ao triângulo $A B D$ por ALA (possuem dois ângulos correspontentes congruentes e lado correspondente congruente);

Demonstração de que o triângulo $A B D$ é semelhante ao triângulo $A E F$ :

$\mathrm{O}$ triângulo $A E F$ é retângulo, pois o ângulo $E \widehat{A} F$ é reto, e o triângulo $A B D$ é retângulo, conforme foi visto anteriormente. Tem-se que a medida do ângulo $F \widehat{E} A$ é igual à medida do ângulo $C \widehat{E} A$ que é igual a $90^{\circ}-\alpha$ (ou seja, o ângulo $C \widehat{E} A$ é complementar ao ângulo $\alpha$ ). Como o ângulo $D \widehat{A} B$ também é complementar ao ângulo $\alpha$ tem-se que os ângulos $F \widehat{E} A$ e $D \widehat{A} B$ são congruentes. Portanto, o triângulo $A B D$ é semelhante ao triângulo $A E F$ por AA (possuem dois ângulos correspondentes congruentes).

\section{Dicas ao professor:}

1. O círculo trigonométrico fornece todos os triângulos retângulos com cateto unitário, e todos os triângulos retângulos com hipotenusa unitária. E o motivo pelo qual o círculo trigonométrico tem raio unitário é justamente pelo fato de ser mais fácil comparar um triângulo qualquer a outro que tenha um dos lados unitário;

2. Observe que no $1^{\circ}$ quadrante: $\operatorname{sen}(\alpha)$ é a medida do cateto oposto ao ângulo $\alpha$ em um triângulo de hipotenusa unitária, $\cos (\alpha)$ é a medida do cateto adjacente ao ângulo $\alpha$ em um triângulo de hipotenusa unitária, $\operatorname{tg}(\alpha)$ é a medida do cateto oposto ao ângulo $\alpha$ em um triângulo de cateto adjacente unitário, $\sec (\alpha)$ é a medida da hipotenusa em um triângulo de cateto unitário adjacente ao ângulo $\alpha$, $\operatorname{cosec}(\alpha)$ é a medida da hipotenusa em um triângulo de cateto unitário oposto ao ângulo $\alpha$ (pois os triângulos $A B D$ e $A C F$ são congruentes, conforme foi visto no exercício 4 da atividade 7.1), e $\operatorname{cotg}(\alpha)$ é a medida do cateto adjacente ao ângulo $\alpha$ em um triângulo de cateto unitário oposto ao ângulo $\alpha$.

Atividade 7.2 (Encontrando relações trigonométricas no círculo 2 envolvendo secante, cossecante e cotangente de um ângulo $\alpha$ ). Esta Atividade tem o propósito de mostrar como é possível encontrar algumas relações trigonométricas no círculo trigonométrico 2. Para realizar esta atividade usaremos as construções feitas na seção 7.

$\mathrm{O}$ uso do círculo trigonométrico 2 possibilita encontrar várias relações trigonométricas usando os conhecimentos adquiridos na seção 7.1. Com o uso deste círculo trigonométrico no software GeoGebra não é preciso fazer um desenho manual para cada situação, e é possível conferir essas relações trigonométricas usando os valores da janela de álgebra para diferentes medidas do ângulo $\alpha$.

Objetivos: Estimular os alunos ao uso de recursos tecnológicos na aprendizagem; mostrar aos alunos como encontrar algumas relações envolvendo a secante, a cossecante e a cotangente de um ângulo $\alpha$ e explicar o motivo pelo qual se utilizam as palavras cossecante e cotangente.

Pré-requisitos: Semelhança e congruência de triângulos; Relações trigonométricas seno, cosseno e tangente; Retas paralelas cortadas por transversal; Pontos no plano cartesiano e conhecimentos mínimos sobre utilização do software GeoGebra.

Material necessário: Equipamento que tenha instalado o software GeoGebra, além do material escolar usual.

Tempo necessário: 4 horas/aula.

Exercício 5. Considere um ângulo $\alpha$ agudo qualquer no círculo trigonométrico 2 construído no software GeoGebra, conforme a Figura 32. Faça as atividades a seguir:

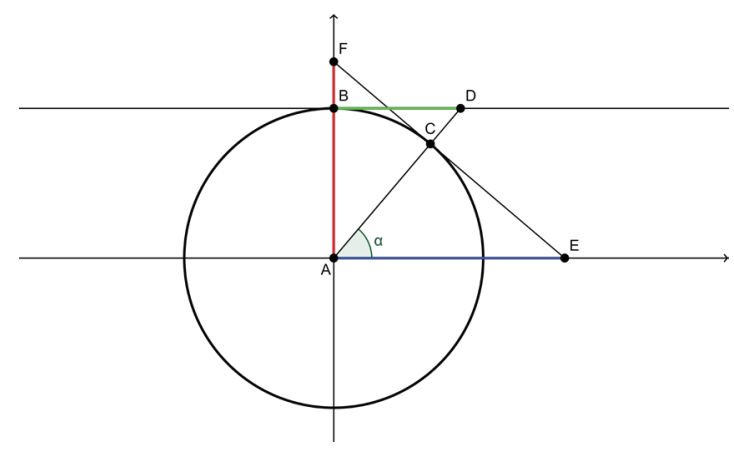

Figura 32: Atividade 7.2, exercício 5

a) Aplique a relação cosseno do ângulo $\alpha$ no triângulo $A C E$ e encontre uma expressão que permita relacionar a secante do ângulo $\alpha$ com o cosseno do ângulo $\alpha$;

b) Aplique a relação seno do ângulo $\alpha$ no triângulo $A C F$ e encontre uma expressão que permita relacionar a cossecante do ângulo $\alpha$ com o seno do ângulo $\alpha$;

c) Aplique a relação tangente do ângulo $\alpha$ no triângulo $A B D$ e encontre uma expressão que permita 
relacionar a cotangente do ângulo $\alpha$ com a tangente do ângulo $\alpha$;

d) Seja $\beta$ o ângulo complementar a $\alpha$. Use a igualdade encontrada no item (b) do exercício 5 da atividade 7.2 , e sabendo que se $\alpha$ e $\beta$ são ângulos complementares então $\operatorname{sen}(\alpha)=\cos (\beta)$, depois use a igualdade encontrada no item (a) do exercício 5 da atividade 7.2, e encontre uma relação entre os ângulos $\alpha$ e $\beta$;

e) Seja $\beta$ o ângulo complementar a $\alpha$. No triângulo $A B D$ aplique a relação tangente do ângulo $\beta$ e encontre uma relação trigonométrica entre os ângulos $\alpha$ e $\beta$.

\section{Dica ao professor:}

1. Mostre que na Figura 32 os segmentos $\overline{A D}$ e $\overline{E F}$ são perpendiculares e, consequentemente, os triângulos $A C E, A C F$ e $A E F$ são semelhantes e os triângulos $A C F$ e $A B D$ são congruentes, conforme foi visto no exercício 4 da atividade 7.1.

\section{Solução da Atividade 7.2:}

Exercício 5

a) Aplicando a relação cosseno do ângulo $\alpha$ no triângulo $A C E$, tem-se:

$$
\cos (\alpha)=\frac{\overline{A C}}{\overline{A F}} \Leftrightarrow \cos (\alpha)=\frac{1}{\sec (\alpha)} \Leftrightarrow \sec (\alpha)=\frac{1}{\cos (\alpha)}
$$

Importante: A secante de um ângulo é igual ao inverso do cosseno desse mesmo ângulo e, consequentemente,

$$
\sec (\alpha)=\frac{\text { hipotenusa }}{\text { cateto adjacente }}
$$

b) Conforme vimos no exercício 4 da atividade 7.1, o ângulo $\alpha=E \widehat{A} D$ é congruente ao ângulo $B \widehat{D} A$, pois são ângulos alternos internos e o ângulo $A \widehat{F} C$ é congruente ao ângulo $B \widehat{D} A$ pois os triângulos $A B D$ e $A C F$ são congruentes. Portanto, como $A \widehat{F C}=\alpha$, aplicando a relação seno do ângulo $\alpha$ no triângulo $A C F$, tem-se:

$\operatorname{sen}(\alpha)=\frac{\overline{A C}}{\overline{A F}} \Leftrightarrow \operatorname{sen}(\alpha)=\frac{1}{\operatorname{cosec}(\alpha)} \Leftrightarrow \operatorname{cosec}(\alpha)=\frac{1}{\operatorname{sen}(\alpha)}$.

Importante: A cossecante de um ângulo é igual ao inverso do seno desse mesmo ângulo e, consequentemente,

$$
\operatorname{cosec}(\alpha)=\frac{\text { hipotenusa }}{\text { cateto oposto }}
$$

c) Conforme vimos no exercício 4 da atividade 7.1, o ângulo $E \widehat{A} D$ é congruente ao ângulo $B \widehat{D} A$, pois são ângulos alternos internos. Portanto, como $B \widehat{D} A=\alpha$, aplicando a relação tangente do ângulo $\alpha$ no triângulo $A B D$, tem-se:

$$
\operatorname{tg}(\alpha)=\frac{\overline{A B}}{\overline{B D}} \Leftrightarrow \operatorname{tg}(\alpha)=\frac{1}{\operatorname{cotg}(\alpha)} \Leftrightarrow \operatorname{cotg}(\alpha)=\frac{1}{\operatorname{tg}(\alpha)} .
$$

Importante: A cotangente de um ângulo é igual ao inverso da tangente desse mesmo ângulo e, consequentemente,

$$
\operatorname{cotg}(\alpha)=\frac{\text { cateto adjacente }}{\text { cateto oposto }} \text {. }
$$

d) Seja $\alpha$ e $\beta$ ângulos complementares. Usando as relações propostas, tem-se:

$$
\operatorname{cosec}(\alpha)=\frac{1}{\operatorname{sen}(\alpha)}=\frac{1}{\cos (\beta)}=\sec (\beta) .
$$

Importante: A cossecante de um ângulo $\alpha$ é igual à secante do ângulo $\beta$ que é complementar a $\alpha$. Diga inclusive, que a palavra "cossecante"é empregada justamente por ser a secante do ângulo complementar.

e) No triângulo $A B D$ o ângulo $D \widehat{A} B$ é complementar ao ângulo $\alpha$, então $D \widehat{A} B=\alpha$. Portanto, aplicando a relação tangente do ângulo $\beta$ no triângulo $A B D$, tem-se:

$$
\operatorname{tg}(\beta)=\frac{\overline{B D}}{\overline{A B}} \Leftrightarrow \operatorname{tg}(\beta)=\frac{\operatorname{cotg}(\alpha)}{1} \Leftrightarrow \operatorname{tg}(\beta)=\operatorname{cotg}(\alpha) .
$$

Importante: A cotangente de um ângulo $\alpha$ é igual à tangente do ângulo $\beta$ que é complementar a $\alpha$. Diga inclusive, que a palavra "cotangente"é empregada justamente por ser a tangente do ângulo complementar.

\section{Dica ao professor:}

1. É importante para o aluno que ele tenha total entendimento das relações trigonométricas encontradas nessa seção, por esse motivo é válido que se façam exercícios usando o círculo trigonométrico 2, onde o aluno possa testar essas relações trigonométricas usando os valores encontrados na janela de álgebra do software Geogebra.

\section{Conclusões}

Ultimamente a sociedade vem passando por grandes problemas. A falta de estrutura familiar, o acesso a conteúdos impróprios para a faixa etária das crianças, falta de orientação, limites e afeto a que muitas crianças e adolescentes são submetidos podem gerar grandes problemas na sua formação intelectual das crianças e adolescentes e também gera problemas em auto-estima e falta de perspectiva de vida. Soma-se a isso o fato de normalmente as escolas manterem métodos tradicionais de ensino em meio a uma sociedade em constante transformação. Isto faz com que a escola não seja atra- 
tiva aos olhos de muitos alunos, gerando desestímulos, reprovação e evasão escolar.

Tornar a escola mais atrativa e estimulante é um grande desafio aos profissionais da educação atualmente. Nesse contexto, os professores de Matemática tem o grande desafio de tornar uma matéria considerada difícil, pela grande maioria dos alunos, em algo acessível, estimulante, capaz de gerar interesse e com um aprendizado satisfatório.

Tentando colaborar com a superação desse grande desafio, através desse trabalho disponibilizou-se aos professores de Ensino Fundamental algumas construções no software GeoGebra e uma proposta de atividades usando-as com intuito de levar os alunos à conclusão das principais relações trigonométricas.

No decorrer deste trabalho foi realizada uma pesquisa bibliográfica em 5 , dos 10 livros didáticos do $9^{\circ}$ ano do Ensino Fundamental, colocados a disposição dos professores da rede pública de ensino pelo MEC (Ministério da Educação e Cultura) através do PNLD 2014 (Programa Nacional do Livro Didático). Nesta pesquisa ficou constatado que, dos livros consultados, nenhum deles menciona a existência do círculo trigonométrico, embora um deles apresente um instrumento para encontrar os valores de seno e cosseno de um ângulo agudo, que é uma reprodução do primeiro quadrante do círculo trigonométrico. Também ficou constatado que, embora um desses livros apresente como usar o programa Microsoft Mathematics, livros que usam recursos tecnológicos são exceções. Além disso, esses livros definem seno, cosseno e tangente apenas para ângulos agudos e nenhum desses livros faz referência à secante, cossecante, e cotangente, quase nada se fala a respeito de outras relações trigonométricas e se detém aos estudos de trigonometria no triângulo retângulo.

Foram apresentadas três atividades: a primeira propõe um exercício com o círculo trigonométrico de Hiparco, a segunda apresenta algumas relações trigonométricas envolvendo seno, cosseno e tangente de um ângulo e a terceira trata das principais relações trigonométricas envolvendo secante, cossecante e cotangente de um ângulo.

Os exercícios de cada atividade estão todos resolvidos, onde se usou as construções no software GeoGebra. A maioria das atividades servem de pré-requisito para a atividade subsequente, portanto torna-se interessante seguir a ordem, mas fica a critério do professor decidir a forma de usar que mais lhe convém e se adapta à turma. O professor também pode criar seus próprios exercícios com as construções do software GeoGebra e uma das possibilidades é testar as relações trigonométricas usando os valores encontrados na janela de álgebra.

A utilização do software GeoGebra e de outras tecnologias no estudo da trigonometria no Ensino Fundamental pode ser um excelente recurso para auxiliar os professores nas suas aulas, tornando-as mais atrativas e significativas aos olhos dos alunos. Além disso, posibilitar a investigação matemática através da observação dos objetos e auxilia a construção do conhecimento de todos os envolvidos no processo de ensino e aprendizagem.

É importante que o professor tenha a sensibilidade de entender as dificuldades de cada turma e elaborar aulas específicas de acordo com elas. Com o uso de recursos tecnológicos, aumenta-se a probabilidade dos alunos se sentirem motivados na aprendizagem da Matemática e, consequentemente, o interesse dos alunos pode aumentar consideravelmente.

\section{Referências}

Bianchini, E. (2012). Matemática, $9^{0}$ ano. Moderna, São Paulo.

Centurión, M., Jakubovic, J. (2012). Matemática: Teoria e Contexto, $g^{\circ}$ ano. Saraiva, São Paulo.

Costa, M. V. (2007). A escola tem futuro? Lamparina, Rio de Janeiro.

Dante, L. R. (1999). Matemática: Contexto e Aplicações (Manual do Professor). Ática, São Paulo.

de Leonardo, F. M. (2013). Projeto Araribá Matemática, $9^{\circ}$ ano. Moderna, São Paulo.

Libâneo, J. C. (2001). Adeus professor, adeus professora? Novas exigências educacionais e profissão docente. Cortez, São Paulo.

MEC (1998). Parâmetros Curriculares Nacionais (5 ${ }^{a}$ a $8^{a}$ séries). URL http://portal.mec.gov.br/seb/ arquivos/pdf/introducao.pdf.

Onaga, D. S., Mori, I. (2012). Matemática: Ideias e Desafios, $9^{\circ}$ ano. Saraiva, São Paulo.

Souza, J., Pataro, P. M. (2012). Vontade de Saber Matemática, $9^{\circ}$ ano. FTD, São Paulo.

Strasburg, E. B. (2014). Atividades de trigonometria para o ensino fundamental com o uso do software geogebra. Dissertação de Mestrado. 